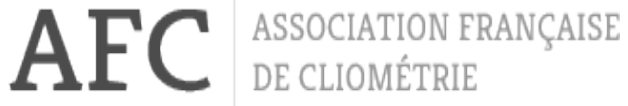

WORKING PAPERS

\author{
Nr. 6, 2012
}

Equity Risk Premium and Time Horizon:

What do the U.S. Secular Data Say?

\section{Georges PRAT}




\title{
EQUITY RISK PREMIUM AND TIME HORIZON: WHAT DO THE U.S. SECULAR DATA SAY?
}

\author{
Georges Prat (georges.prat@u-paris10.fr) \\ February 2012
}

\begin{abstract}
We consider a representative investor whose wealth is made up of the equity market portfolio and the riskless asset, and who maximizes the expected utility of his/her future wealth for a given horizon. The solution of this program shows that the equilibrium value of the equity risk premium - the latter being measured by the difference between the expected equity portfolio return and the risk-free interest rate - is given by the product of the price of risk and the expected variance of stock returns. When returns are predictable, these two magnitudes are both time-varying and horizondependent. In accordance with this theoretical framework, our paper presents an econometric model of equity risk premia for two traditional horizons: the one-period-ahead horizon (i.e. the 'short-term' premium) and the infinite-time horizon (i.e. the 'long-term' premium). Using annual US secular data from 1871 to 2008, and representing the expected returns by mixing the three traditional adaptive, extrapolative and regressive processes, large disparities in the dynamics of the two premia are evidenced. Concerning the determination of the equilibrium values of the two premia, the expected variances depend on the past values of the centered squared returns while the prices of risk (unobservable variables) are estimated according to the Kalman filter methodology, which enables us to capture the influence of hidden variables and of non-directly measurable psychological effects. A spread of interest rates adds to this determination. Possibly due to risky arbitrage and transaction costs, the results show that observed premia gradually converge towards their equilibrium values, this process being described by an error correction model. Overall, our model provides a rather satisfactory representation of 'short-term' and 'long-term' premia.
\end{abstract}

\section{PRIME DE RISQUE DES ACTIONS ET HORIZON D'INVESTISSEMENT: QUE NOUS ENSEIGNENT LES DONNEES SECULAIRES AMERICAINES ?}

Résumé - On considère un investisseur représentatif dont la richesse est constituée du portefeuille de marché et de l'actif sans risque, et qui maximise sur un horizon donné l'utilité espérée de sa richesse future. La solution de ce programme montre que la valeur d'équilibre de la prime de risque - cette dernière étant mesurée par la différence entre la rentabilité anticipée du portefeuille de marché et le taux d'intérêt sans risque - est déterminée par le produit du prix du risque par la variance anticipée de la rentabilité des actions. Lorsque les rentabilités sont prévisibles, ces deux dernières grandeurs dépendant à la fois de la date et de l'horizon. Dans ce cadre théorique, et en utilisant les données séculaires annuelles américaines sur la période 1871-2008, cet article propose un modèle économétrique des primes de risque des actions pour deux horizons : l'horizon d'une période (prime « de court terme») et horizon infini (prime «de long terme»). Les rentabilités espérées étant représentées par les processus traditionnels adaptatif, extrapolatif et régressif, on observe des différences importantes entre ces deux primes au cours de la période considerée. Concernant les valeurs d'équilibre des deux primes, les variances anticipées dépendent des valeurs passées du carré des rentabilités (centrées) tandis que le prix du risque (variable inobservable) est déterminé suivant la méthode du filtre de Kalman, pouvant ainsi permettre de capturer l'influence de facteurs cachés et d'effets psychologiques non directement mesurables; un spread de taux d'intérêt enrichit cette détermination. Enfin, un modèle à correction d'erreur montre que les primes observées s'ajustent progressivement sur leurs valeurs d'équilibre, ce phénomène pouvant être attribué au risque d'arbitrage et aux coûts de transactions. Au total, le modèle proposé donne une représentation assez satisfaisante des primes de court et de long terme.

JEL classification: D81; D84; E44; G11; G12

Key words: equity risk premium, time horizon 


\section{EQUITY RISK PREMIUM AND TIME HORIZON: WHAT DO THE U.S. SECULAR DATA SAY?}

\section{1 - Introduction}

A thorough understanding of the market equity risk premium is a major challenge for both theoretical and empirical reasons. ${ }^{1}$ At theoretical level, a key input in asset allocation models is the value of the market equity risk premium (e.g. the CAPM); in fact, these models are pretty much inoperative without a valid estimate of this premium. At empirical level, stock market capitalization is highly sensitive to the value of the risk premium since a one percent shift in the latter can add or subtract a trillion dollars to the US stock market value. ${ }^{2}$ However, a multitude of premia has to be taken into consideration. In effect, investors in equity markets intervene with different decision-making time horizons: e.g., intra-day or daily traders, individual non-professional portfolio managers, long-term institutional investors such as pension funds, etc. The point is that when returns are unpredictable, there is a single risk premium, but when stock returns are predictable, risk premia are horizon-dependent. In this last context, equities are exchanged between agents requiring different risk premia, although the market clearing condition gives a single market price. ${ }^{3}$ Anufriev and Bottazzi (2004) discussed the conditions of existence of a market equilibrium price in a multiple horizon framework and showed that, using suitable parameterization, the no-arbitrage market condition leads to a stable fixed point. ${ }^{4}$ Over the last fifteen years, heterogeneity models have been developed while distinguishing fundamentalists and chartists. ${ }^{5}$ While the fundamentalists are often viewed as reflecting the behaviour of long-term investors and the chartists the behaviour of short-term investors, the investment's time horizon was rarely explicitly taken into account for measuring and modelling equity risk premia. The little

\footnotetext{
${ }^{1}$ The author thanks David Le Bris and two anonymous readers of this review for their relevant comments on a first version of this paper.

${ }^{2}$ See Graham and Harvey (2003).

${ }^{3}$ Let $P_{\tau}^{*}$ be the virtual price related to investors with horizon $\tau$ and $n_{\tau}$ the number of equities held by this class of investors. With a number $h$ of independent horizons, the market clearing condition for an equity priced $P$ may be written as $\sum_{\tau=1}^{h} n_{\tau}\left(P-P_{\tau}^{*}\right)=0$ with $\sum_{\tau=1}^{h} n_{\tau}=\mathrm{N}$, where $\mathrm{N}$ refers to the total number of equities. This leads to $P=\sum_{\tau=1}^{h} a_{\tau} P_{\tau}^{*}$ with $a_{\tau}=\frac{n_{\tau}}{N}$ and $\sum_{\tau=1}^{h} a_{\tau}=1$.

${ }^{4}$ Subbotin (2009) gives a survey of the rare literature on this point.

${ }^{5}$ Among others, see Brock and Hommes (1998), Boswijk et al. (2007).
} 
attention given to this important source of heterogeneity in the stock market is somewhat astonishing insofar as the literature on interest term structure shows that time horizon matter considerably in the value of the required risk (or term) premium: why should it not be the same for the stock market? Our paper aims to shed some additional light on this question.

The rest of the paper is organized as follows. Part 2 gives a brief survey of the literature on equity risk premiums and indicates the novel features of our study with respect to the literature. Part 3 presents our theoretical framework which allows us to express the equilibrium value of an equity risk premium for a given horizon as the product of the expected variance of returns and the price of risk associated with the horizon. Part 4 presents assumptions for the determination of expectations (returns and variances) and for the prices of risk. Using US secular data from 1871 to 2008, Part 5 presents the estimation of the equilibrium premia given by the Kalman filter methodology for the one-period-ahead and the infinite time horizons, and shows that, possibly due to risky arbitrage and transaction costs, an error correction model is useful to represent the gradual adjustment of premia towards their equilibrium values. Part 6 concludes.

\section{2 - Brief survey of the literature on equity risk premium and novel aspects of this study}

A common way of measuring the equity risk premium is to consider over a long time period the average of the difference between the observed stock market return and the riskfree interest rate, in other words, the excess return, also known as the "ex-post risk premium". At theoretical level, the well-known debate about the "equity premium puzzle" refers to empirical results based on this approach: with reasonable values of preference parameters (i.e. the risk aversion coefficient and the subjective discount rate), the theoretical risk premium inferred from the consumption asset-based general equilibrium model is far too low (about 1$2 \%$ a year) compared to the observed ex-post premium, which stands at about 6-7\% a year on average (Mehra and Prescott (1985)). ${ }^{6}$ The debate needs to be supplemented by the three main properties of equity risk premia, which will be considered in the model proposed hereafter: premia are ex-ante, time-varying and horizon-dependant magnitudes.

\footnotetext{
${ }^{6}$ Papers by Kocherlakota (1996), Cochrane (1997) and Siegel and Thaler (1997) provide comprehensive surveys of the literature related to the equity premium puzzle and attempts to solve this puzzle (see also Prat, 2007).
} 
Long-term averages hide in fact hide large variations in excess returns. Dimson, Marsh and Staunton (2003) report that premiums were generally higher during the second half of the $20^{\text {th }}$ century, while Siegel (2005) shows that the average premium was substantially lower during the periods $1802-1870$ (3.2\%) and 1871-1925 (4.00\%). On the other hand, Ibbotson Associates (2006) find the value of 7.1\% for the period 1926-2005. Overall, we can see that these equity premium values vary significantly depending on the period, and this led Shiller (2000) to point out that "the future will not necessarily be like the past," while Fernandez (2006, p.12) concludes that “... equity premium change over time and it is not clear why capital market data from the $19^{\text {th }}$ century or from the first half of the $20^{\text {th }}$ century may be useful in estimating expected returns in the $21^{\text {st }}$ century...." Further evidence of the time-varying character of equity risk premium is of course given by the many conditional variance models. As early as 1987, French et al. showed that monthly risk premia fluctuations on the US stock market are partly driven by the conditional variance of returns (ARCH effects), while the paper by Koutmos et al. (2008) gives a recent illustration of this approach using daily stock returns for European countries. Adopting another approach, De Santis and Gerard (1997) analysed the dynamics of premia by using a conditional multivariate CAPM, while the study by Kryzanowski et al. (1997), based on the conditional Arbitrage Pricing Theory, focuses on the macroeconomic factors of the time-varying equity premia for a set of 130 mutual funds equities on the Canadian market. ${ }^{7}$

\section{Ex-post versus ex-ante risk premia}

An equity premium is defined by the difference between the expected return of the risky asset at time $t$ for a given time horizon and an equivalent horizon risk-free rate: a risk premium is clearly an ex-ante concept. However, the empirical studies quoted above refer to the ex-post risk premium as an excess return based on the return observed over a given future time span, and this gives rise to two main difficulties. First, since investors make their financial choices on the basis of their required ex-ante premium, the ex-post premium is not a straightforward

\footnotetext{
${ }^{7}$ According to these studies, there is an implicit assimilation between the frequency of observation in returns and the time horizon of the investment, which is a simplifying assumption. For instance, Benartzi and Thaler (1995) suggested that long-term investors can adopt myopic behaviour since they observe returns over periods shorter than the horizon. Conversely, studies modelling high frequency data using GARCH specifications suggest that the one-period-ahead expected variance depends on the squared returns from many lagged returns.
} 
decision-making concept, unless the perfect foresight hypothesis holds. However, under this last condition, it is clear that there is no risk premium. Second, the excess return equals the underlying risk premium plus the forecasting error and this is likely to generate severe econometric biases when the error is not a white noise, i.e. when returns are not expected rationally. ${ }^{8}$ In fact, survey data show that there are large and systematic forecasting errors imbedded in experts' expected returns for various short horizons (i.e. inferior or equal to 12 months), ${ }^{9}$ and this report suggests that the excess return is not a good proxy of risk premium. Following another approach, Fama and French (2002) measure long-term ex-ante risk premium on the US stock market (S\&P index) using the dividends (or earnings) discount model (DDM). According to the Gordon formula, this premium equals the dividend yields plus the expected long-term dividends growth rate minus the risk-free rate. The authors infer the expected dividends growth rate (or earnings) per share and the risk-free rate from historical mean values of dividends (earnings) and interest rates respectively. Interestingly, Fama and French found a mean premium of around $2.5 \%$ per annum for the period extending from 1951 to 2000 . As a result, and contrary to what is obtained with excess returns, the DDM leads to equity premia approaching the value predicted by the consumption-based asset-pricing model, hence confirming that large unexpected returns are included in the excess returns (i.e. in the ex-post premia). ${ }^{10}$ Overall, and in line with the conclusion of Wander et al. (1988), these results show that it is important to respect the ex-ante character of the risk premium.

\footnotetext{
${ }^{8}$ This is probably why the values of ex-post premia are as often negative as positive (among others, see MpackoPriso (2001)). This may also explain why studies using lagged predictors to forecast excess equity returns (dividend yield, earnings price ratio, short-term interest rate, payout ratio, term and default spreads of interest rates, inflation rate, book-to-market ratio, consumption, wealth,...) can find no robust predictors (see Goyal and Welch 2003, 2007), hence confirming that the ex-post premium is probably more of a countable observation than an operational concept.

${ }^{9}$ See Cowles (1933), Lakonishok (1980), Brown and Maital (1981), Pearce (1984), Taylor (1988), Dokko and Edelstein (1989), Mpacko (1992), MacDonald and Marsh (1992), Fraser and MacDonald (1993), Prat (1994), and Abou and Prat (1997). More recently, using semi-annual S\&P industrial expectations 6 and 12 months ahead, carried out by J. Livingston's surveys on a panel of experts, Abou and Prat (2010) calculated risk premia over the period 1952 to 1993 using these data, and showed that these premia are time-varying with an average of $2.3 \%$ per year, hence approaching the value predicted by the consumption-based asset-pricing model.

${ }^{10}$ The study by Harris and Marston (2001) is also based on the Gordon formula, where the expected growth in earnings per share issued from surveys approximates the expected growth in dividends, while the risk-free rate yield is represented by long-term US government bonds. For the S\&P 500 over the period 1982-98, the authors show strong evidence that this risk premium changes over time and that a significant part of its dynamics may be explained by readily available, forward-looking proxies for risk, such as interest rates spreads, the consumer confidence index reported by the Conference Board, the degree of discrepancy between financial analysts' forecasts, or the implicit volatility issued from options prices. However, the period appears too limited to provide reliable results.
} 


\section{Equity premium and time horizon}

Merton (1969), Samuelson (1969) and Py (1973) early analyzed the relation between the time-life horizon and portfolio risk, and showed that, if returns are unpredictable, rational investors characterized by a constant relative risk aversion require a risk premium which is not horizon dependant. ${ }^{11}$ However, if returns are predictable, this result no longer prevails. In fact, there is a body of existing empirical studies which provides evidence that returns are somewhat forecastable. $^{12}$ Interestingly, Barberis (2000) illustrates the link between predictability and the detention of risky assets while building optimal portfolios made up of stocks and bonds quoted on the US market. Barberis shows that, taking into account the predictable feature of stock returns based on past values of dividend yield, the optimal portfolio is reached by $40 \%$ of stocks for a one-month horizon and by $100 \%$ of stocks for a 10 -year horizon. When returns are supposed to be unpredictable, the share of stocks is near $35 \%$ whatever the horizon. These results suggest that the horizon of investment is a significant factor in determining the required equity risk premium measured by the spread between stock return and bond yield. ${ }^{13}$ In fact, since the 1970 s, practitioners refer to equity risk premia based on cash flow expectations (by financial analysts) or expected stock returns (by experts), these premia being calculated for different horizons. For example, Wells Fargo (2011) calculates the implied 10-year equity risk premium as the difference between the UBS and the Credit Suisse expected S\&P 500 long-run return minus the 10-year treasury yield. ${ }^{14}$ Especially since the years 2000, academic work using survey data revealing experts' stock return expectations straightforwardly confirms the existence of a time-varying term structure for equity risk premia. Thus, studies by Welch $(2000,2001)$ and Prat (2001) show that, despite common trends, substantial discrepancies characterize risk premia depending on the

\footnotetext{
${ }^{11}$ More recently see Gollier and Zeckhauser (2002) who extended this approach.

${ }^{12}$ Beyond the existence of a "short memory" in stock returns (i.e. autocorrelation), economic variables such as interest rates spreads, change in money supply, production growth, change in corporate earnings, the dividend/earnings ratio and dividend yield are sometimes shown to be significant predictors for different horizons. Among others, see Fama \& French (1988), Poterba \& Summers (1988), Lo \& MacKinlay (1988), Kandel and Stambaugh (1991, 1996), Brennan and Xia (2005), and Goyal and Welch (2003, 2007). In particular, Fama \& French (1988) show that the power of dividend yields to forecast stock returns increases with the time horizon (more recently, see Shanken and Tamyo (2011)). Cochrane (1999a) gives an overview of the predictable character of stock returns. Moreover, some authors have shown the existence of a "long memory" in stock returns which also suggests predictability (see Lo (1991), Triki and Selmi (2009) and the survey by Henry (2002)).

${ }^{13}$ The appendix gives an example illustrating why the predictability of returns leads to a time-varying and horizon-dependant set of premia.

${ }^{14}$ For the French stock market, see for example "Associés en Finance" (1997) and Hamon \& Jacquillat (1999) who consider $e x$-ante risk premia based on expected return related to a sample consisting of the main 150 stocks quoted on the Paris Bourse (1986 - 1998).
} 
time horizon. ${ }^{15}$ Moreover, Graham and Harvey (2001-2010) present a set of permanent studies about expected equity premia defined as the difference between the experts' mean expected stock returns and an equivalent horizon's bond yields. These studies are based on quarterly surveys conducted since June 2000 by Duke University and CFO Magazine, and concern stock market returns expected by about 270 anonymous Chief Financial Officers (CFOs) from U.S. corporations. The authors found that, in contrast to the 10-year expected risk premium, the one-year risk premium is highly erratic through time, ranging from 1.3 to $6.6 \%$, depending on the quarter surveyed. As a result, these studies strongly confirm that exante premia are both time-varying and horizon-dependent.

\section{Novel aspects of this paper}

This brief overview of the literature suggests to build a model where ex-ante risk premia are both time-varying and horizon-dependent. In this perspective, our paper is original in several ways. First, we consider the equilibrium risk premium required by a representative investor whose wealth is made up of an equity market portfolio and the riskless asset, and who maximizes the expected utility of his/her future wealth for a given horizon. Possibly due to transaction costs and risky arbitrage, observed premia may gradually converge towards their equilibrium values. Second, in accordance with this theoretical framework, and using annual US secular data from 1871 to 2008 , equity risk premia are modelled simultaneously for two polar horizons: the one-period-ahead horizon (i.e. the 'short-term' premium) and the infinite time horizon (i.e. the 'long-term' premium). Third, the question of equity risk premia measurement - which involves hypotheses about the representation of expected returns - and the question of their explanation are solved within the same model. Fourth, since the supposed time-varying short- and long-term prices of risk are non observable variables, these magnitudes are represented using the Kalman filter methodology, while information contained in a spread of interest rates can also intervene.

\section{3 - Equity risk premia and time horizon: a simple theoretical framework}

Many observers consider that international stock markets had little influence on the US stock market during the $20^{\text {th }}$ century, which suggests that the US market corresponds

\footnotetext{
${ }^{15}$ Abou and Prat (2010) give an overview of studies concerned with ex-ante equity premia issued from survey data.
} 
roughly to the segmented market hypothesis during this period. ${ }^{16}$ In this context, let us consider a representative investor who holds a combination of the risk-free asset and the US stock market portfolio $^{17}$ (this is the risky asset), whose returns are $R_{o, t}$ and $R_{t}$, respectively. The share of the risky asset is $\Theta_{t}\left(0 \leq \Theta_{t} \leq 1\right)$, while the utility $U\left(W_{t}\right)$ of the investor at time $t$ is an increasing function of his/her wealth $W_{t}\left(U^{\prime}>0\right)$. This function has a concave form $\left(U^{\prime \prime}<0\right)$ with an absolute risk aversion coefficient $\lambda_{t}=\frac{-U^{\prime \prime}\left(W_{t}\right)}{U^{\prime}\left(W_{t}\right)}>0$. The investor should determine the value of $\theta_{t}$ in order to maximise the expected utility of his/her wealth at time $t$ for the 'next period', conditional to a given set of information $\Omega_{t}$. Put in expectation-variance form, the investor's program is

$$
\underset{\theta_{t}}{\operatorname{Max}} Q_{t}=E\left[W_{t+1}\left(\theta_{t}\right) \mid \Omega_{t}\right]-\frac{\lambda_{t}}{2} \operatorname{Var}\left[W_{t+1}\left(\theta_{t}\right) \mid \Omega_{t}\right] \quad 0 \leq \theta_{t} \leq 1
$$

where $E\left[W_{t+1}\left(\theta_{t}\right) \mid \Omega_{t}\right]$ and $\operatorname{Var}\left[W_{t+1}\left(\theta_{t}\right) \mid \Omega_{t}\right]$ stand for the expectation and the variance of the wealth respectively. Given the identity $W_{t+1}=W_{t}\left(\theta_{t} R_{t+1}+\left(1-\theta_{t}\right) R_{o t}\right)$, the two first moments of wealth distribution are:

$$
\begin{aligned}
& E\left[W_{t+1}\left(\theta_{t}\right) \mid \Omega_{t}\right]=W_{t}\left(\theta_{t} E\left[R_{t+1} \mid \Omega_{t}\right]+\left(1-\theta_{t}\right) R_{o t}\right) \\
& \operatorname{Var}\left[W_{t+1}\left(\theta_{t}\right) \mid \Omega_{t}\right]=W_{t}^{2} \theta_{t}^{2} \operatorname{Var}\left[R_{t+1} \mid \Omega_{t}\right]
\end{aligned}
$$

where $R_{t+1}$ is the return of the risky asset between $t$ and $t+1$ while $R_{o, t}$ stands for the oneperiod-to-maturity risk-free rate. Reporting (2) and (3) into (1), the program can be written as follows:

$$
\begin{aligned}
& \left.\underset{\theta_{t}}{\operatorname{Max}} Q_{t}=W_{t}\left(\theta_{t} E\left[R_{t+1}\right) \mid \Omega_{t}\right]+\left(1-\theta_{t}\right) R_{O t}\right)-\frac{\lambda_{t}}{2} W_{t}^{2} \theta_{t}^{2} \operatorname{Var}\left[R_{t+1} \mid \Omega_{t}\right] \\
& \text { The first order condition } \frac{d Q_{t}}{d \theta_{t}}=0 \text { gives }
\end{aligned}
$$

\footnotetext{
16 This leads many authors to consider the American stock price index as a suitable proxy of the Word stock price index. However, for the years 2000, this approximation is probably somewhat less precise.

17 Concerning asset management practices, since the market portfolio can be traded directly with low management costs using the popular Exchange Traded Funds (ETF) "Shares S\&P 500 index", this indicates that the expected return of this index is a straightforward relevant magnitude for investors.
} 


$$
\left.W_{t}\left(E\left[R_{t+1}\right) \mid \Omega_{t}\right]-R_{o t}-\varphi_{t} \theta_{t} \operatorname{Var}\left[R_{t+1} \mid \Omega_{t}\right]\right)=0
$$

where $\varphi_{t}=\lambda_{t} W_{t}$ is the relative risk aversion coefficient. This condition leads to the following equilibrium value of the equity risk premium defined by the difference between the expected one-period-ahead stock return and the risk-free rate:

$$
\left.E\left[R_{t+1}\right) \mid \Omega_{t}\right]-R_{o t}=\gamma_{t} \operatorname{Var}\left[R_{t+1} \mid \Omega_{t}\right] \quad \gamma_{t}>0
$$

where $\gamma_{t}=\varphi_{t} \theta_{t}$ represents the price of risk. Since the condition $\frac{d^{2} Q_{t}}{d \theta_{t}^{2}}=-W_{t} \varphi_{t} \operatorname{Var}\left[R_{t+1} \mid \Omega_{t}\right]<0$ holds, we check that the first order condition corresponds to a maximum. According to (4), the equilibrium risk premium must be positive, since it is determined at any one time by the product of the price of risk and the expected variance of the risky asset.

It is worth noting that relation (4) says nothing about the set of information $\Omega_{t}$ used by the investor to make stock return and variance expectations. If the stock price level contains all the relevant information (i.e. the price is expected rationally), then the efficient market hypothesis holds, and the return is a white noise with constant mean and variance, and then is unpredictable. As a result, if the price of risk is independent of the state of the nature, the expected return, the variance and thus the risk premium are constant, so that any attempt to model the expected time-varying return and risk premium is not a good challenge. On the other hand, if the price is not expected rationally, returns are predictable and the expected return and risk premium are time-varying and horizon-dependant. ${ }^{18}$ In this latter context, any empirical work requires hypotheses about the question of the representation of expectations

\footnotetext{
${ }^{18}$ On this point, Cochrane (2011) argues that the time-varying character of the expected return is a main starting point. To illustrate this, assume for simplicity that dividends are null, so that the market price is the discounted value of the future expected price, that is $P_{t}=\lambda E\left[P_{t+1} \mid \Omega_{t}\right]$ where $0<\lambda<1$ is the constant time-preference factor. We can write $E\left[P_{t+1} \mid \Omega_{t}\right]=P_{t+1}\left(1+\varepsilon_{t+1}\right)$ where $\varepsilon_{t+1}$ is the relative forecast error. Reporting the latter into the former relation, we get $R_{t+1}=c+\varepsilon_{t+1}^{\prime}$, where $R_{t+1}=\ln \frac{P_{t+1}}{P_{t}}, c=-\ln \lambda>0$ and $\varepsilon_{t+1}^{\prime}=-\varepsilon_{t+1}$. Under the rational expectation hypothesis ( $\Omega_{t}$ represents all relevant information), $\varepsilon_{t+1}^{\prime}$ is a white noise (zero mean and constant variance), so that the return equals a constant term plus a white noise. This implies that the expected return equals the constant average return, while the expected variance of return equals the variance of the error term, so that the risk premium is constant. But if $\Omega_{t}$ conveys a limited set of information, that is, if stock price expectations are not rational, the return is predictable using any observable variables included in the forecast error. This implies that the expected return and the risk premium are time-varying and horizon-dependent (see Appendix).
} 
(see §4). Another issue lies in the fact that relation (4) leaves the value of the 'next period', corresponding to the time horizon of the investor unspecified, and this implies that this relation holds whatever the value of the horizon. In this paper, two traditional representative horizons are considered: the one-year horizon (since we consider annual data) that will be called the 'short-term' horizon and the infinite time horizon that will be called the 'long-term' horizon. In the literature, these two horizons are analysed most often, probably by convenience. However, another reason should be considered here. Because this choice extends to the maximum the time span between the short- and long-term horizons, it allows to support the assumption of independence between the behaviour of short-term and long-term investors. This condition is indeed necessary to consider the determination of short-term and long-term premia separately in conformity with the general relation (4).

The risk premium characterizing the short-term investor's behaviour is defined as

$$
\Phi_{1 t}=E\left[R_{t+1} \mid \Omega_{t}\right]-R_{o t}
$$

where $R_{t}=\frac{P_{t}-P_{t-1}+D_{t}}{P_{t-1}}$ represents the one-year stock return, while $R_{o, t}$ stands for the oneyear-to-maturity risk-free rate, both expressed in percent per annum. The risk premium characterizing the long-term investor's behaviour is deduced from the dividend discount model with an infinite horizon. The expected one-year return being $E\left[R_{t+1} \mid \Omega_{t}\right]=\frac{E\left[P_{t+1} \mid \Omega_{t}\right]-P_{t}+E\left[D_{t+1} \mid \Omega_{t}\right]}{P_{t}}=R_{o t}+\Phi_{1 t}$, the forward iterative resolution of this last equation leads to the following well-known expression of stock price in an infinite timehorizon framework:

$$
P_{t}=E_{t} \sum_{k=0}^{\infty} D_{t+k} \prod_{j=0}^{k} \frac{1}{\left(1+R_{t+j}\right)} \quad \text { with } \quad R_{t}=R_{o t}+\Phi_{1 t}
$$

According to (6), the price equals the present value of the expected stream of future dividends. ${ }^{19}$ Supposing that the expected rate of growth in dividends and the actualization rate are uniform between $t$ and all the successive periods $t+k$, we obtain the well-known "GordonShapiro" stock valuation formula from which we can deduce the risk premium $\Phi_{2 t}$ characterizing long-term investor behaviour (expressed in percent per annum):

\footnotetext{
${ }^{19}$ When expectations are assumed to be rational (6), it gives the fundamental value of equities. Under the transversality condition, there is no bubble and the price equals the fundamental value plus a white noise.
} 


$$
\Phi_{2 t}=E\left[R_{t, \infty} \mid \Omega_{t}\right]-\bar{R}_{o t} \quad \text { with } \quad E\left[R_{t, \infty} \mid \Omega_{t}\right]=\frac{D_{t}\left(1+\bar{g}_{t}\right)}{P_{t}}+\bar{g}_{t}
$$

where $E\left[R_{t, \infty} \mid \Omega_{t}\right], \bar{g}_{t}$ and $\bar{R}_{o t}$ stand for the long-term expected stock return, the expected long-term rate of growth in dividends and the long-term riskless rate of interest, respectively. Note that, according to (7), the implicit stock return for the long-term investor is $R_{t, \infty}=\frac{D_{t}}{P_{t}}+g_{t}$ with $g_{t}=\frac{D_{t}-D_{t-1}}{D_{t-1}}$.

While the short- and long-term premia $\Phi_{1 t}$ and $\Phi_{2 t}$ are defined by (5) and (7), these two premia are determined in accordance with the general relation (4). With indexes 1 and 2 indicating the one-year and infinite time horizon, respectively, we can write:

$$
\begin{aligned}
& \Phi_{1 t}=E\left[R_{t+1} \mid \Omega_{t}\right]-R_{o t}=\gamma_{1 t} \operatorname{Var}\left[R_{t+1} \mid \Omega_{t}\right] \\
& \Phi_{2 t}=\frac{D_{t}\left(1+\bar{g}_{t}\right)}{P_{t}}+\bar{g}_{t}-\bar{R}_{o t}=\gamma_{2 t} \operatorname{Var}\left[R_{t, \infty} \mid \Omega_{t}\right]
\end{aligned}
$$

\section{4 - Assumptions about expected returns, expected variances and prices of risk representations}

To check the validity of equations (8) and (9) empirically, assumptions about the representation of the expected stock return for the one-period horizon and the expected dividends growth rate for the infinite horizon are needed on the left-hand sides, while assumptions about the expected variances and the prices of risk are needed on the right-hand sides. This implies that, according to our approach, the measurement (on the left) and the explanation (on the right) of risk premia are modelled simultaneously.

\section{The expected returns}

As mentioned above, many empirical studies suggest that returns are somewhat forecastable. ${ }^{20}$ Concerning our set of US secular data, a brief analysis of the autoregressive character of $R_{t}$ and $g_{t}$ suggests that mixing the three traditional extrapolative, adaptive and

\footnotetext{
${ }^{20}$ See note (12).
} 
regressive processes could be a way to represent expectations. ${ }^{21}$ It is worth noting that this result is reinforced with expected returns revealed by survey data which show that mixing these three processes may be a valuable approach. ${ }^{22}$ Accordingly, we will assume that expectations are represented by a combination of these three traditional processes. While all three processes appeared significant for the one-year horizon, only the adaptive and regressive processes appeared significant for the infinite horizon. The expectation processes are thus as follows:

One-year horizon

$$
E\left[R_{t+1} \mid \Omega_{t}\right]-R_{t}^{m}=a_{1,1}\left(\bar{R}-R_{t}\right)+a_{1,2}\left(R_{t}-R_{t-1}\right)+a_{1,3}\left(R_{t-1}-R_{t-2}\right) \quad, \quad a_{1, j}>0
$$

with

$$
R_{t}^{m}=\beta_{1} R_{t}+\left(1-\beta_{1}\right) R_{t-1}^{m} \quad 0 \leq \beta_{1} \leq 1
$$

Infinite horizon

$$
\bar{g}_{t}-g_{t}^{m}=a_{2,1}\left(\bar{g}-g_{t}\right) \quad, \quad a_{2,1}>0
$$

with

$$
g_{t}^{m}=\beta_{2} g_{t}+\left(1-\beta_{2}\right) g_{t-1}^{m}, \quad 0 \leq \beta_{2} \leq 1
$$

Equations (10) and (11) indicate that the expected rates of return ${ }^{23}$ are determined by mixing an adaptive component ( $R_{t}^{m}$ and $g_{t}^{m}$, which are on the left-hand sides), a regressive component (first terms on the right-hand sides) and extrapolative components, the latter being significant only for the short-term horizon (second and third terms on the right-hand side in (10)). The coefficients $\beta_{1}, \beta_{2}, a_{1, i}(i=1,2,3)$ and $a_{2,1}$ are determined in the course of the estimation of the equilibrium risk premia model.

\footnotetext{
${ }^{21}$ We obtain the following results $(1882-2008)$ :

$$
\begin{aligned}
& R_{t}=\underset{(1.92)}{0.17}\left(R_{t-1}-R_{t-2}\right)+\underset{(2.81)}{0.68\left(\bar{R}-R_{t-1}\right)}+\underset{(4.20)}{10.25}+\underset{(2.40)}{0.59} \varepsilon_{t-1}+\varepsilon_{t} ; R^{2}=0.07 \\
& g_{t}=\underset{(1.94)}{0.27}\left(\bar{g}-g_{t-1}\right)+\underset{(2.25)}{3.52}+\underset{(3.42)}{0.61} \zeta_{t-1}+\zeta_{t} ; \quad R^{2}=0.11
\end{aligned}
$$

Concerning $R_{t}$, the extrapolative and regressive components are significant, while the residuals appeared to follow an MA(1), hence suggesting the possibility of an adaptive process (Muth, 1960). Concerning $g_{t}$, we obtain similar results but without the extrapolative component.

${ }^{22}$ See Prat (1994) and Abou \& Prat (2000).

${ }^{23}$ Equation (7) shows that knowledge of the expected growth rate in dividends $\bar{g}_{t}$ allows us to determine the long-term expected return. 


\section{The expected variances}

We now turn to the conditional expected variances. The Appendix illustrates why the expected variance is horizon-dependent when the returns are predictable and shows that, according to the date, the short-term premium may be greater or smaller than the long-term premium. An ARCH-M model would not be suitable to represent expected variances since such an approach would describe the conditional volatility of the risk premium equation residuals and not the total variance of the return, as required by our model. ${ }^{24}$ Along the same lines as other studies, ${ }^{25}$ the expected variances are represented by weighted averages of the past values of the centred-squared returns, this latter representing a proxy of the instantaneous variance: ${ }^{26}$

One-year horizon: $\quad \operatorname{Var}\left(R_{t+1} \mid \Omega_{t}\right)=\frac{\sum_{i=1}^{m} \alpha_{1, i} \sigma_{1 t-i}^{2}}{\sum_{i=1}^{m} \alpha_{1, i}}, \quad \alpha_{1,1}=1 ; \alpha_{1, \mathrm{i}}>0$
Infinite horizon: $\quad \operatorname{Var}\left(R_{t, \infty} \mid \Omega_{t}\right)=\frac{\sum_{i=1}^{m^{\prime}} \alpha_{2, i} \sigma_{2 t-i}^{2}}{\sum_{i=1}^{m} \alpha_{2, i}}, \quad \alpha_{2,1}=1 ; \alpha_{2, i}>0$

with $\sigma_{1 t}^{2}=\left(R_{t}-\bar{R}\right)^{2}$ and $\sigma_{2 t}^{2}=\left(R_{t, \infty}-\bar{R}_{\infty}\right)^{2}$, where $\bar{R}$ and $\bar{R}_{\infty}$ are averages of $R_{t}$ and $R_{t, \infty}$, respectively. ${ }^{27}$ The parameters $\alpha_{1, i}, \alpha_{2, i}, m$ and $m$ ' are determined in the course of the estimation of the risk premia model. Note that, Graham and Harvey (2001-2007) asked

\footnotetext{
${ }^{24}$ An ARCH model, where the mean equation specifies the stock return as a constant term plus an error term, would give a first-step estimation of the conditional expected variance, but this estimation would be disconnected from the estimation of the portfolio model. Moreover, annual data are generally inappropriate for implementing an $\mathrm{ARCH}$ process, the latter generally being adapted to at least monthly data.

${ }^{25}$ Among others, following Bollerslev (1987), Hansen and Lunde (2005) suggest representing the expected variance by an ARMA model for the squared returns while including a constant term. Müller et al. (1997) refer to a specification similar to (12) and (13).

${ }^{26}$ We also considered the actual value of the instantaneous variance $(i=0)$ in (12) and (13), but this assumption lowered the risk premia model information criteria compared to the retained specification $(i=1)$ where the expected variance is determined only by the past values of the observed variance. Moreover, we retained the possibility to add a constant term in the right-hand side of the equations. However, for both equations, these constants appeared insignificant and were then removed.

${ }^{27}$ The centred squared returns $\sigma_{1 t}^{2}$ and $\sigma_{2 t}^{2}$ appeared to be insignificantly autocorrelated over the sample period. We added an intercept on the right-hand side of (12) and (13), but this parameter was found to be insignificant. Note that the expected variances are expressed on an annual basis since they are defined as weighted averages (this is because the two premia are in \% per annum).
} 
questions designed to determine an expert's assessment of market volatility, based on CFO surveys. Interestingly, the latter appeared much lower than usual alternative measures, suggesting that, in accordance with hypotheses (12) and (13), expected variance has a lower magnitude than observed variance.

\section{The prices of risk}

The prices of risk $\gamma_{1 t}$ and $\gamma_{2 t}$ are not only unobservable variables, but remain variables whose factors are a priori unknown. To circumvent this problem, we implement a State-Space model in which, for each horizon, a signal equation describes the risk premium while a state equation contributes to the determination of the unobservable price of risk. The state variables $s v_{1 t}$ and $s v_{2 t}$ generated by the state equations capture the influence on the price of risk of hidden factors and of non-directly measurable psychological effects. The two state equations are $\mathrm{AR}(1)$ processes, possibly augmented by a constant drift and by macroeconomic variables such as the rate of inflation, the rate of growth in real consumption per capita and in earnings-per-share, and various interest rate spreads. As a result, only the rate of change in corporate earnings per share appeared to be significant for the long-term price of risk. Moreover, when added to the state equation, the relative spread $S_{t}$ between the yield of 30-year high-grade corporate bonds and the yield of 10-year government bonds appeared significant in the determination of the only long-term price of risk, ${ }^{28}$ while a constant term was found significant only for the short-term price of risk. As a result, the prices of risk $\gamma_{1 t}$ and $\gamma_{2 t}$ are determined according to the following relations:

The price of risk for the one-year time horizon

$$
\begin{array}{ll}
\gamma_{1 t}=s v_{1 t}+\kappa_{1} & \\
s v_{1 t}=\rho_{1} s v_{1 t-1}+\eta_{1 t} & 0 \leq \rho_{1} \leq 1
\end{array}
$$

The price of risk for the infinite time horizon

$$
\begin{array}{ll}
\gamma_{2 t}=s v_{2 t}+\delta_{2} S_{t} & \delta>0 \\
s v_{2 t}=\rho_{2} s v_{2 t-1}+b_{2} \frac{\Delta B_{t}}{B}+\eta_{2 t} & 0 \leq \rho_{2} \leq 1, b>0
\end{array}
$$

\footnotetext{
${ }^{28}$ This is not very astonishing insofar as the spread concerns long-term bonds.
} 
where $S_{t}=\frac{\bar{R}_{c t}-\bar{R}_{o t}}{\bar{R}_{c t}}, \bar{R}_{c t}$ and $\bar{R}_{o t}$ representing the 30 -year corporate bond yield and the $10-$ year government bond yield respectively, where $\frac{\Delta B_{t}}{B}$ stands for the rate of change in earnings-per-share, where errors $\eta_{1 t}$ and $\eta_{2 t}$ are Gaussian white noises, and where $\kappa_{1}$ is an intercept. The spread $S_{t}$ captures the risk of default since corporate bonds are more risky assets than government bonds; but $S_{t}$ also captures risk due to different maturities, since corporate bonds are 30 years to maturity while government bonds are 10 years to maturity. Our intuition is not that $S_{t}$ directly influences the equity risk premia, but rather that economic uncertainty factors influencing $S_{t}$ also intervene in the price of risk determination (the coefficient $\delta_{2}$ is expected to be positive). ${ }^{29}$ The positive expected influence of change in earnings-per-share $\left(b_{2}>0\right)$ may be due to the fact that an increase in corporate earnings incites investors to raise the share of the risky asset in their portfolios, thereby leading to a rise in the long-term price of risk.

\section{5 - Equity risk premia and time horizon: empirical evidence}

We used annual secular data over the period 1871 to 2008 which are available on Robert Shiller's website (“Annual data on US Stock Market”). $P_{t}$ is the January Standard and Poor's 500 stock price index, $D_{t}$ and $B_{t}$ are the S\&P dividends and earnings-per-share during last year, $R_{o t}$ the one-year interest rate, and $\bar{R}_{o t}$ the 10 -year government bonds yield. We also extended a 30-year high-grade corporate bond yield time series over this period by using Friedman and Schwartz (1982) data. ${ }^{30}$ Data concerning $P_{t}, D_{t}$ and $B_{t}$ were discussed and revised by Wilson and Jones (2002) (WJ) over the period 1870 to 1999 . Note that unlike Shiller's annual database, the WJ series are for December of each year. Comparing Shiller's December S\&P stock price index and dividends \& earnings (also given on Shiller's website) with the WJ data, we observed that the series are somewhat confused from 1957 to 1999. However, during the period 1870 to 1956 , WJ values appeared to be at a slightly larger level

\footnotetext{
${ }^{29}$ A number of contributions have shown that interest rate spreads are negatively (positively) correlated with stock prices (returns). Concerning the spread between different US bond yield ratings over a long period, see in particular Prat (1982), Chapter IV which is entirely devoted to this relation. Concerning the link between spread and different US bond yield maturities and equity risk premium through the APT, see, among others Chen, Roll and Ross (1986) and Elton, Gruber and Mei (1994)) and Kryzanowski et al. (1997).

${ }^{30}$ Friedman and Schwartz (1982), Table 6.17, pp. 296. These data end in 1975, but we have updated them.
} 
compared to Shiller's data, although the two data sets exhibit very similar movements. To appreciate if there is significant bias in using one data set rather than another, we compared the annual stock returns (including dividends) over the period 1871-1957 calculated from Shiller' S\&P with the stock returns calculated from the WJ data. The two measures appeared to be closely correlated. Regressing Shiller' S\&P returns on the WJ returns, the regression coefficient was found to be insignificantly different from one and the intercept insignificantly different from zero, the residuals being insignificantly autocorrelated. As a result, with regard to our study, either the Shiller or the WJ data can be used indifferently.

Reporting the expressions of the expected return (10), of the expected variance (12) and of the price of risk (14) in the structural relation of the short-term premium (8), and adding a Gaussian noise $v_{1 t}$ independent of the auxiliary residuals $\eta_{1 t}$ in the state equation, we get the signal equation (18) for the short-term premium, which is estimated simultaneously with the state equation (15):

$$
R_{t}^{m}-R_{o t}=-a_{1,1}\left(\bar{R}-R_{t}\right)-a_{1,2}\left(R_{t}-R_{t-1}\right)-a_{1,3}\left(R_{t-1}-R_{t-2}\right)+\left(s v_{1 t}+\kappa_{1}\right) \frac{\sum_{i=1}^{m} \alpha_{1, i} \sigma_{1 t-i}^{2}}{\sum_{i=1}^{m} \alpha_{1, i}}+v_{1 t}(18
$$

$s v_{1 t}=\rho_{1} s v_{1 t-1}+\eta_{1 t}$

For given values of $\beta_{1}$ and of the initial value of $R_{t}^{m},(18)$ and (15) allow us to identify the values of the one-year premium, which is the observed short-term premium

$$
\Phi_{1 t}=E\left[R_{t+1} \mid \Omega_{t}\right]-R_{o t}
$$

where

$$
E\left[R_{t+1} \mid \Omega_{t}\right]=\left[R_{t}^{m}+a_{1,1}\left(\bar{R}-R_{t}\right)+a_{1,2}\left(R_{t}-R_{t-1}\right)+a_{1,3}\left(R_{t-1}-R_{t-2}\right)\right]
$$

represents the one-year expected return. The estimation of equations (18) and (15) allow us to determine the theoretical equilibrium short-term premium at the same time

$$
\Phi_{1 t}^{*}=\left(s v_{1 t}+\kappa_{1}\right) \frac{\sum_{i=1}^{m} \alpha_{1, i} \sigma_{1 t-i}^{2}}{\sum_{i=1}^{m} \alpha_{1, i}}
$$


In a similar manner, reporting the expressions of the expected rate of dividends growth (11), of the expected long-term variance (13) and of the long-term price of risk (16) in the structural relation of the long-term premium (9), and adding a Gaussian noise $v_{2 t}$ independent of the auxiliary residuals $\eta_{2 t}$ in the state equation, we get the signal equation (22) for the longterm premium, which is estimated simultaneously with the state equation (17)

$$
\begin{aligned}
& \frac{D_{t}\left(1+\bar{g}_{t}\right)}{P_{t}}+g_{t}^{m}-\bar{R}_{o t}=-a_{2,1}\left(\bar{g}-g_{t}\right)+\left(s v_{2 t}+\delta_{2} S_{t}\right) \frac{\sum_{i=1}^{m^{\prime}} \alpha_{2, i} \sigma_{2 t-i}^{2}}{\sum_{i=1}^{m} \alpha_{2, i}}+v_{2 t} \\
& s v_{2 t}=\rho_{2} s v_{2 t-1}+b_{2} \frac{\Delta B_{t}}{B}+\eta_{2 t}
\end{aligned}
$$

For given values of $\beta_{1}$ and of the initial value of $g_{t}^{m},(22)$ and (17) allow us to identify the value of the observed infinite time premium

$$
\Phi_{2 t}=\frac{D_{t}\left(1+\bar{g}_{t}\right)}{P_{t}}+g_{t}^{m}+a_{2,1}\left(\bar{g}-g_{t}\right)+-\bar{R}_{o t}
$$

where

$$
\bar{g}_{t}=g_{t}^{m}+a_{21}\left(\bar{g}-g_{t}\right)
$$

represents the long-term expected rate of dividends growth. The estimation of equations (22) and (17) allow us to determine the theoretical equilibrium long-term premium at the same time

$$
\Phi_{2 t}^{*}=\left(s v_{2 t}+\delta_{2} S_{t}\right) \frac{\sum_{i=1}^{m^{\prime}} \alpha_{2 i} \sigma_{2 t-i}^{2}}{\sum_{i=1}^{m} \alpha_{2 i}}
$$

For given values of $\beta_{1}, \beta_{2}$ and initial values of expected variables, the 4-equationssystem (18), (15), (22) and (17) can be estimated jointly as a system using the Kalman filter methodology, ${ }^{31}$ where (18) and (22) are the two signal equations, while (15) and (17) are the two state equations. Due to correlations between the two premia and between their factors, a

\footnotetext{
${ }^{31}$ For the Kalman filter methodology, see Harvey (1992), Ch. 3 and Hamilton (1994), Ch.13.
} 
contemporaneous correlation exists between innovations $v_{1 t}$ and $v_{2 t}$, which could cause estimation bias. However, the joint estimation of the 4-equations system allows us to account for these possible biases since a covariance term covar between $v_{1 t}$ and $v_{2 t}$ is estimated among the set of hyperparameters. All parameters (including initial values of state variables) are those minimizing the Akaike, Schwarz and Hannan-Quinn information criteria.

\section{[ Insert Table 1]}

Table 1 gives descriptive statistics of the two observed premia determined by equations (19) and (20) for the one-year premium and by equations (23) and (24) for the infinite horizon premium, with optimal values $\beta_{1}=7 \%$ and $\beta_{2}=3 \%$ respectively. ${ }^{32}$ These coefficients which characterize the adaptive components of expected returns show a relatively long delay of influence for the two horizons, the longer delay found for the long-run horizon being somewhat intuitive. It is worth noting that, except at the beginning of 1980s, the values of the premia retain positive values. In addition to error measurements, the negative values observed in 1980 could be due to the shock of the Republican Presidential election of Ronald Reagan, reinforced at the same time by the Republican majority elected in the Senate. If these events had an effect on equity risk premia, it was probably in the direction of a fall. The shorttem premium appears to be higher in mean, and this result correlates with the fact that shortterm returns are much more volatile than long-term returns. Interestingly, the mean value of the infinite horizon premium (2.3\% per year) is close to the value of $2.5 \%$ obtained by Fama and French (2002). Figures 1 and 2 exhibit the time patterns of the components of the observed premia for the one-year and the infinite time horizon, respectively. Interestingly, in both cases, the components appear to be a non negligible one compared to the others. Figure 3 compares the values of the two observed premia: although these two magnitudes are stationary at the $10 \%$ level of significance, the horizon appears as a very discriminant parameter, conditioning the dynamics of the premia (the value of $R^{2}=0.25$ is not very high), and this result confirms the lessons drawn from survey data (see part 2).

\section{[ Insert figure 1]}

\section{[ Insert figure 2]}

\section{[ Insert figure 3]}

\footnotetext{
${ }^{32}$ The optimal initial values of the adaptive components of expected return (in (18)) and of the expected rate of growth in dividends (in (22)) are found to be $4 \%$ and $0 \%$ per year, respectively.
} 
Table 2 gives the estimates of the structural model of risk premia estimated with the Kalman filter methodology. Concerning the signal equations, a grid search over the lags $m$ and $m$ ' intervening in the expected variances determination led to the optimal values of 6 and 8 years for the one-year and the infinite horizon, respectively. Standard errors of estimates suggest that coefficients $\alpha_{\tau, i}$ are not significantly different from 1 at the 5\% level, hence suggesting that the expected variances could be approached with a simple arithmetic average of past values of centred squared returns. Figure 4 compares the time patterns of the two expected variances, and confirms that, despite similar trends $\left(R^{2}=0.43\right)$, the short-term expected variance is more volatile than the long-term one. The significant positive value obtained for the covariance between the residuals $v_{1 t}$ and $v_{2 t}$ of the two signal equations (covar) is due to the correlations between the two premia, between the two expected variances and between the two state variables, as displayed in Figures 3, 4 and 7, respectively. The covariance between the two state residuals $\eta_{1 t}$ and $\eta_{2 t}$ was found to be insignificantly different from zero, which is why this covariance has been removed from the estimations. ${ }^{33}$

\section{[ Insert Table 2]}

\section{[ Insert figure 4]}

Another point is that, as expected, the coefficient $\delta_{2}$ of the spread of interest rates $S_{t}$ is significantly positive, which is in line with the results in the literature. ${ }^{34}$ Consequently, for the long-term premium, the spread contributes - with the state variable $s v_{2 t}$ - to the representation of the price of risk. Since this paper is concerned with a structural model, the state variables are estimated at each point in time, conditional on the whole sample data (smoothed inference), rather than only using past observations (predicted inference). At each point of time, the Kalman filter method yields the standard deviations of each state variable, $s t d_{t, i}$ for $i=1,2$. For an accepted $5 \%$ level of significance, the $s t d_{t, i}$ allows us to determine a zone of uncertainty defined at each date by the line ranging between the estimated value plus and minus $1.96 s t d i_{t}$. In the same manner, the constant standard deviation of coefficients of $\delta_{2}$ enable us to define a zone of uncertainty associated with $\delta_{2} S_{t}$, for the long-term premium. These standard deviations allow us to associate upper and lower bounds to the estimated

\footnotetext{
${ }^{33} \mathrm{We}$ also found a zero covariance between the signal residuals and the state residuals for each horizon. This was a condition for updating state equations.

${ }^{34}$ See note (29).
} 
values of the price of risk $\gamma_{1 t}$ and $\gamma_{2 t}$, as shown by Figures 5 and 6, respectively. It is worth noting that the estimated values of $\gamma_{1 t}$ and $\gamma_{2 t}$ are rarely negative although no constraint was imposed, and this result is rather satisfying since the theoretical value of the price of risk is positive. ${ }^{35}$ Figure 7 shows that, although the short-term and long-term prices of risk are somewhat correlated ( $R^{2}=0.09$ ), they exhibit large own fluctuations. It can be seen that the expected variances and the prices of risk can explain both sudden changes and periods of high or low premia, and this allows us to understand why it is not necessary to consider structural changes explicitly over this long period.

\section{[ Insert figure 5]}

\section{[ Insert figure 6]}

The conventional $R^{2}$ between the observed and fitted values given by the signal equation (Table 2) show that $85 \%$ of the variance is explained for the short-term horizon and $77 \%$ for the long-term horizon. We further checked the quality of the fits by using a modified measure, $R_{D}^{2}$, assessing the relevance of our model with respect to a benchmark represented by a simple random walk plus drift. ${ }^{36}$ The values of $R_{D}^{2}$ are 0.36 and 0.24 for the long- and the short-term horizons respectively (Table 2), indicating that our risk premia model clearly outperforms the benchmark. We now turn to the statistical properties of the estimated values of the standardized residuals of the signal equations $\left(v_{1 t}\right.$ and $\left.v_{2 t}\right)$. Although the p-value of the Jarque-Bera statistics (JB) allow us to accept the normal distribution hypothesis, ${ }^{37}$ the $p$ values associated with the F-statistic of the Ljung-Box Q test show that the null of no serial correlation is rejected for the two horizons, the autocorrelations being of first rank. These

\footnotetext{
${ }^{35}$ Note that, because returns are conventionally expressed in percent, they are multiplied by $10^{2}$ and the variances by $10^{4}$ compared to their theoretical decimal values, respectively. Consequently, if the theoretical decimal values had been considered, the estimated values of $\gamma_{1 t}$ and $\gamma_{2 t}$ would have been equal to hundred times the values represented on figures 5,6 and 7. As shown in these figures, this implies that the theoretical values of the prices of risk fluctuate around a mean close to 2 (more precisely 1.9 and 1.7 for $\gamma_{1 t}$ and $\gamma_{2 t}$ respectively), what seems rather realistic values (recall that the price of risk is the product of the relative risk aversion coefficient and the share of the risky asset in the portfolio).

${ }^{36}$ Whereas $R^{2}=1-S S R / \sum_{t=1}^{T}\left(y_{t}-\bar{y}\right)^{2}$, we have $R_{D}^{2}=1-\operatorname{SSR} / \sum_{t=2}^{T}\left(\Delta y_{t}-\overline{\Delta y}\right)^{2}$ where $y_{t}=\Phi_{\tau t}(\tau=1,2)$

while $S S R$ is the sum of the squared residuals. A negative $R_{D}^{2}$ implies that the estimated model is less precise than a simple random walk plus drift (Harvey, 1992).

${ }^{37}$ This result shows that there are not a significant number of abnormal values.
} 
results suggest that, beyond a possible specification bias, market friction factors such as transaction $\operatorname{costs}^{38}$ and risky arbitrage ${ }^{39}$ could cause delayed adjustments of premia towards their theoretical equilibrium values. To check this assumption, we estimate simple error correction models (ECMs), where the observed premia $\Phi_{1 t}$ and $\Phi_{2 t}$ are given by equations (19) and (23), while equilibrium premia $\Phi_{1 t}^{*}$ and $\Phi_{2 t}^{*}$ (i.e. the targets ${ }^{40}$ ) are given by equations (21) and (25), respectively: ${ }^{41}$

$$
\begin{aligned}
& \Delta \Phi_{1 t}=\underset{(6.1)}{0.38}\left(\Phi_{1 t-1}^{*}-\Phi_{t-1}\right)+\underset{(27.2)}{1.05} \mu_{1} \Delta \Phi_{1 t}^{*}+\hat{\varepsilon}_{1 t} \quad R^{2}=0.41 \\
& Q \text { test (4 lags): } p=0.45 ; \text { ARCH test }(1 \text { lag): } p=0.31 ; \text { JB test }: p=0.09 \\
& \Delta \Phi_{2 t}=\underset{(6.8)}{0.42}\left(\Phi_{2 t-1}^{*}-\Phi_{2 t-1}\right)+\underset{(29.0)}{1.02} \Delta \Phi_{2 t}^{*}+\hat{\varepsilon}_{2 t} \\
& Q \text { test (4 lags): } p=0.52 ; \text { ARCH test }(1 \text { lag): } p=0.02 ; \text { JB test }: p=0.31
\end{aligned}
$$

The ECMs (26) and (27) are estimated simultaneously with the Seemingly Unrelated Regression method, which is robust to the contemporaneous correlation between the two residuals and for a possible heteroskedasticity of residuals. The Ljung-Box Q test applied on the estimated values of residuals $\varepsilon_{1 t}$ and $\varepsilon_{2 t}$ now leads us to accept the null of no autocorrelation at the 5\% level of significance. Moreover, for both residuals, the p-value associated with the Jarque-Bera statistics allow us to accept the hypothesis of a normal distribution, while, according to ARCH tests, the null of no heteroskedasticity is not rejected at the $5 \%$ level for $\hat{\varepsilon}_{1 t}$ or at the $1 \%$ level for $\hat{\varepsilon}_{2 t}$. These results suggest that the residuals have good properties. Interestingly, it can be seen that the coefficients estimated for the variation in the targets are found to be close to unit, suggesting that, when the error correction term is null, changes in observed premia are described by changes in the equilibrium premia only. Figures 8 and 9 represent the observed and fitted values of the premia issued from the MCE (26) and (27), respectively: ${ }^{42}$ The model fits well with the main fluctuations of the short-term and long-

\footnotetext{
${ }^{38}$ See Anderson (1997).

${ }^{39}$ See Shleifer and Summers (1990).

${ }^{40}$ For both horizons, we found that neither the lagged values of the endogenous variables nor macroeconomic variables such as interest rates, rate of growth of industrial production, inflation rate and changes in earningsper-share was significant.

${ }^{41}$ Using the ADF unit root test, we checked that the differences $\Phi_{1 t}-\Phi_{1 t}^{*}$ and $\Phi_{2 t}-\Phi_{2 t}^{*}$ are stationary at the $5 \%$ level of significance. This result suggests that $\Phi_{1 t}^{*}$ and $\Phi_{2 t}^{*}$ can be considered as targets.

${ }^{42}$ We have $\hat{\Phi}_{\tau t}=\Delta \hat{\Phi}_{\tau t}+\Phi_{\tau t-1}$ with $\Delta \hat{\Phi}_{\tau t}=\Delta \Phi_{\tau t}-\hat{\varepsilon}_{\tau t}$.
} 
term premia. Overall, these results suggest that equity risk premia gradually adjust towards their equilibrium values, hence confirming the relevance of the estimated equilibrium values.

\section{6 - Concluding remarks}

An equity premium is the difference between the expected return of an equity portfolio for a given time horizon and an equivalent maturity risk-free interest rate. At theoretical level, we consider a representative investor whose wealth is made up of an equity market portfolio and of a riskless asset, and who maximizes the expected utility of his or her future wealth for a given horizon. The solution of this program is that, for a given horizon, the theoretical equilibrium value of the premium at time $t$ equals the price of risk times the expected variance of returns. Using annual US secular data from 1871 to 2008 , the challenge of our study compared to the literature was to simultaneously model the measurements and explanations of ex-ante equity risk premia for both time horizons, that are the one-year-ahead horizon (the 'short-term' premium) and the infinite horizon (the 'long-term' premium).

Representing expected returns by mixing the three traditional extrapolative, adaptive and regressive processes, large disparities in the dynamics of the two observed premia are evidenced, as expected when the stock returns are predictable. The expected variances are found to depend on the past values of variances over periods of 5 and 8 years for the shortterm and long-term premia, respectively. For each horizon, the price of risk is determined by an unobservable variable, determined according to the Kalman filter methodology (i.e. a state variable), which is assumed to capture the influence of hidden variables and of non-directly measurable psychological effects. For the long-term horizon, a spread of interest rates capturing economic factors of uncertainty also contributes to representing the price of risk. Consequently, it is shown that the estimated equilibrium values can be considered as valuable targets while, possibly due to risky arbitrage and transaction costs, an error correction model shows that observed premia tend towards their targets. This model offers a valuable representation of the short-term and long-term premia over the period 1881-2008, and then gives an explanation of the large disparities in their dynamics. Overall, these results shed some additional light on the existence of a time-varying term structure of equity risk premia and suggest simultaneously solving their measurement and their explanation, although results will in any case be conditional on the hypothesis retained for the expected return representation. 


\section{Appendix - Why are equity risk premia time-varying and horizon-dependant when returns are predictable? An illustration}

It is supposed that no dividends are distributed. Let $p_{t}$ denote the logarithm of the price of an equity or a portfolio at time $\mathrm{t}$ and $\Delta$ the 1-period change operator. Suppose that the return is unpredictable since $\Delta p_{t}$ is a white noise plus a possible constant drift. ${ }^{43}$ In this case, we have $E\left(p_{t+\tau}-p_{t}\right)=\tau E\left(\Delta p_{t+1}\right)$ and $\operatorname{Var}\left(p_{t+\tau}-p_{t}\right)=\tau V\left(\Delta p_{t+1}\right), \tau \geq 1$, that is, the first two moments increase in the same proportion as $\tau$. Since the risk premium depends on the expected variance (see equation (4)), the premium averaged per period is neither timevarying nor $\tau$ dependent for a constant price of risk, so there is a single and constant premium. Conversely, when returns are partially predictable on the basis of their past values and/or macroeconomic variables, ${ }^{44}$ it can be shown that the risk premium is both time-varying and horizon-dependent.

As a simple example, suppose that the one-period return is related to the variable $\Delta X_{t}$ according to the relation $\Delta p_{t+1}=\alpha \Delta X_{t}+\eta_{t+1}(\alpha \neq 0)$, where $\Delta X_{t}$ stands for any regressor possibly including $\Delta p_{t}$ such that $\operatorname{Cov}\left(\Delta X_{t+1} ; \Delta X_{t}\right)=\kappa \forall t$, and where $\eta_{t+1}$ is a white noise uncorrelated with $\Delta X_{t}$ for all lags with $V\left(\eta_{t}\right)=\omega^{2}$. Assuming further, for the sake of simplification, that $V\left(\Delta X_{t}\right)=\theta^{2} \forall t$ and $\operatorname{Cov}\left(\Delta X_{t+\tau} ; \Delta X_{t}\right)=0 \quad \forall \tau>1$, it is then easy to write the variances averaged per period for different time horizons:

1 period: $\quad V\left(\Delta p_{t+1}\right)=\alpha^{2} \theta^{2}+\omega^{2}$

2 periods: $\frac{1}{2} V\left(p_{t+2}-p_{t}\right)=\frac{1}{2} V\left(\Delta p_{t+1}+\Delta p_{t+2}\right)=\theta^{2}+\alpha^{2} \kappa$

3 periods: $\frac{1}{3} V\left(p_{t+3}-p_{t}\right)=\frac{1}{3} V\left(\Delta p_{t+1}+\Delta p_{t+2}+\Delta p_{t+3}\right)=\theta^{2}+\frac{4}{3} \alpha^{2} \kappa$

or, more generally: $\frac{1}{\tau} V\left(p_{t+\tau}-p_{t}\right)=\theta^{2}+2\left(1-\frac{1}{\tau}\right) \alpha^{2} \kappa$

Now relax the assumption $V\left(\Delta X_{t}\right)=\theta^{2} \forall t$ and let $V\left(\Delta X_{t}\right)$ be, for example, an AR(p) process, as usually observed with returns data. It can then be shown that $V\left(p_{t+\tau}-p_{t}\right)$ follows

\footnotetext{
${ }^{43}$ Even if we introduce a discount rate with constant variance which is independent of the white noise forecast error, this conclusion is still valid.

${ }^{44}$ See notes (12) and (21).
} 
an autoregressive structure with order $\mathrm{p}$ when $\tau=1$ and greater than $\mathrm{p}$ when $\tau>1 .{ }^{45}$ This latter result shows that risk premia are time-varying, and sheds light on the assumption that the expected variance depends on past values of observed variances, as supposed in (12) and (13). Moreover, it can be seen that when $\kappa>0$, the variance, and thus the required premium, increases with the horizon, while when $\kappa<0$, the variance and the premium decreases with the horizon. Cochrane (1999) assumes the special case $\Delta X_{t-1}=\Delta p_{t-1}$ and argues that a sufficient condition to generate a horizon-dependent variance is the existence of a serial correlation in returns. More generally, if the covariance $\kappa$ is time-varying, the slope of the term structure of the premia is also time-varying.

\section{REFERENCES}

Abou A. and G. Prat (1997), A propos de la rationalité des anticipations boursières : quel niveau d'agrégation des opinions?, Revue d'Economie Politique, 5, 647-69.

Abou A. and G. Prat (2000), Modelling stock price expectations: lessons from micro data, in Price Expectations in Goods and Financial Markets, Gardes and Prat Editors, London: Edward Elgar, 313-46.

Abou A. and G.Prat (2010), "The Dynamics of U.S. equity premia: lessons from professionals' view," Bankers, Markets and Investors, $\mathrm{n}^{\circ} 104, \mathrm{Jan}-\mathrm{Feb} 2010,4-20$.

Associés en Finance (1997), "La pensée unique en finance: l'exemple de la prime de risque," Lettre Financière, $\mathrm{N}^{\circ} 29$, juin.

Anderson H.M. (1997), "Transaction Costs and Nonlinear Adjustment towards Equilibrium in the US Treasury Bill Markets," Oxford Bulletin of Economics and Statistics, 59, 465-484.

Anufriev M. and G. Bottazzi (2004), “Asset pricing model with heterogeneous investment horizons," Laboratory of Economics and Management (LEM) Working Paper Series, 2004/22, Sant'Anna School for Advanced Studies, Pisa, Italy.

Bancel F. et Ceddaha F. (1999), "Vers une prime de risque unique," Cahiers de recherche de l'ESCP, série Economie et Finance, $n^{\circ}$ 99-143, 28 p.

Barberis N. (2000), "Investing for the long run when returns are predictable," Journal of Finance, 55 (1), 225-64.

Benartzi S. and R. Thaler (1995), Myopic loss aversion and the equity premium puzzle, Quarterly Journal of Economics, 110, 73-92.

Bollerslev T. (1987), " $Z$ conditional heteroskedastic time series model for speculative prices and rates of return," Review of Economics and Statistics, 69(3), 542-47.

\footnotetext{
${ }^{45}$ Proof available upon request.
} 
Boswijk H.P., C.H. Hommes and S. Manzan (2007), "Behavioral Heterogeneity in Stock Prices," Journal of Economic Dynamic and Control, 31(6), 1938-70.

Brennan M.J. and Y. Xia (2005), "Persistence, Predictability and Portfolio Planning,” Finance Research Letters, 2, 1-14.

Brock W.A. and C.H. Hommes (1998), "Heterogeneous beliefs and routes to chaos in a simple asset pricing model," Journal of Economic Dynamic and Control, 22, 1235-74.

Brown B.W. and S. Maital (1981), "What do economists know?" An empirical study of experts' expectations, Econometrica, 49(2), 491-504.

Chen N.F., R. Roll and S. Ross S. (1986), "Economic forces and the stock market: testing the APT and alternative asset pricing theories," The Journal of Business, 59, 383-403.

Cochrane J.H. (1999a), "New facts in finance," Economic Perspectives, Federal Bank of Chicago Review, Third Quarter, 23 (3), 36-58.

Cochrane J.H. (1999b), "Portfolio advice for a multifactor world," Economic Perspectives, Federal Bank of Chicago Review, Third Quarter, 23 (3), 59-78.

Cochrane J.H. (2011), "Discount rates," University of Chicago, Presidential address at the AFA meeting January, http://onlinevideoservice.com/clients/afa/2011/01082011-c.html

Cowles A. (1933), “Can stock market forecasters forecast?” Econometrica, 1(3), 309-24.

De Santis G. and B. Gerard. (1997), "International asset pricing and portfolio diversification with time varying risk," Journal of Finance, 52, 1881-1912.

Dimson E., P. Marsh and M. Staunton (2003), "Global Evidence on the risk premium," Journal of Applied Corporate Finance, 15(4), pp.27-38.

Dokko Y. and R.H. Edelstein (1989), "How well do economists forecast stock market prices? A study of the Livingston surveys," American Economic Review, 79(4), 865-71.

Elton E.J, M.J. Gruber and J. Mei (1994), "Cost of capital using Arbitrage Pricing Theory: a case study of nine New York Utilities," Financial Markets, Institutions and Instruments, 3, 46-73.

Fama E.F. and K.R. French (1988), "Dividends yields and expected stock returns," Journal of Financial Economics, 22(1), 3-25.

Fama E.F. and K.R. French (2002), “The equity premium,” Journal of Finance, 57(2), 637-59.

Fernandez P. (2006), "Equity premium: historical, expected, required and implied," IESE Business School, University of Navarra, Working Paper $n^{\circ} 661$, December.

Fraser P. and R. MacDonald (1993), "The efficiency of CAC stock price forecasts: a survey based perspective," Revue Economique, 5, 991-1000.

French K.R., G.W. Schwert and R.F. Stambaugh (1987), "Expected returns and volatility," Journal of Financial Economics, 19, 3-29.

Friedman M. and A.J. Schwartz (1982), "Monetary trends in the United States and the United Kingdom, Their relation to income, prices and interest rates, 1867-1975," NBER, University of Chicago Press, Chicago, 192. 
Goyal A. and I. Welch (2003), "Predicting the equity premium with dividends ratios," Management Science, 49(5), 639-54.

Goyal A. and I. Welch (2007), "A Comprehensive look at the empirical performance of equity premium prediction," Review of Financial Studies, 2007.

Gollier C. and R. Zeckhauser (2002), "Time horizon and portfolio risk," The Journal of Risk and Uncertainty, 24(3), 195-212.

Graham J.R. and C.R. Harvey (2001), "Expectations of equity risk premia, volatility and asymmetry from a corporate finance perspective," November 30, available at SSRN http://ssrn.com/abstract=292623.

Graham J.R. and C.R. Harvey (2003), "Expectations of equity premia, volatility and asymmetry," Working Paper, Duke University, USA.

Graham J.R. and C.R. Harvey (2005), "The long-run equity premium," Finance Research Letters, 2, 185-194.

Graham J.R. and C.R. Harvey (2007), "The equity risk premium in January 2007: evidence from the global CFO outlook survey," Financial Risk Management, 4, 46-61. The results are still extended in a WP of the Duke University dated 2010.

Hamilton J.D. (1994), Time series analysis, Princeton University Press, Princeton, New Jersey.

Hamon J. and B. Jacquillat (1999), "Is there added-value information in liquidity and risk premiums?" European Financial Management, 5(2), 369-93.

Hansen P. and A. Lunde (2005), "A forecast comparison of volatility models: does anything beat a Garch (1,1)?” Journal of Applied Econometrics, 20(7), 873-89.

Harris R.S. and F.C. Marston (2001), “The market risk premium: expectational estimates using analysts' forecasts," Journal of Applied Finance, 11(1), 6-15.

Harvey A.C. (1992), Forecasting, structural time series models and the Kalman filter, Cambridge University Press, Cambridge.

Henry O.T. (2002), "Long memory in stock returns: some international evidence," Applied Financial Economics, 12(10), 725-29.

Ibbotson Associates (2006), Stocks, Bonds, Bills, and Inflation, Valuation Edition, Yearbook.

Kandel S. and R.F. Stambaugh (1991), “Asset returns and intertemporal preferences,” Journal of Monetary Economics, 27(1), 39-71.

Kandel S. and R.F. Stambaugh (1996), "On the predictability of stock returns; An asset allocation perspective," Journal of Finance, 51(2), 385-424.

Kocherlakota N.R. (1996), “The equity premium: It's still a puzzle?” Journal of Economic Literature, $34,42-71$.

Koutmos G., J. Knif and C. Philipatos (2008), "Modeling common volatility characteristics and dynamic risk premia in European equity markets," Quarterly Review of Economics and Finance, 48, $567-578$. 
Kryzanowski L., S. Lalancette and M.C. To (1997), "Performance attribution using an APT with prespecified macro factors and time-varying risk premia and betas," Journal of Financial and Quantitative Analysis, 32(2), 205-24.

Lakonishok J. (1980), "Stock market expectations: some general properties," The Journal of Finance, 35(4), 921-31.

Lo A.W. (1991), “Long-term memory in stock market prices,” Econometrica, 59, 1279-1313.

Lo A.W. and A.C. MacKinlay (1988), "Stock market prices do not follow random walks: evidence from a single specification test," Review of Financial Studies, 1, 41-66.

MacDonald R. and I.W. Marsh (1992), "The efficiency of spot and futures stock indices: a survey based perspective," Review of Futures Markets, 12(2), 431-454.

Mehra R. and E. Prescott (1985), "The equity premium: a puzzle," Journal of Monetary Economics, 15, $145-61$.

Merton R.C. (1969), "Lifetime portfolio selection under uncertainty: the continuous-time case," Review of Economics and Statistics, 51(3), 247-57.

Mpacko-Priso A. (2001), La prime de risque des actions, Théories et Applications, Dianoïa, Paris.

Müller U., M. Dacorogna, R. Dave, R. Olsen O. Pictet and J. Von Weizsacker (1997), "Volatilities of different time resolutions - analysing the dynamics of market components," Journal of Empirical Finance, 4, 213-39.

Muth J.F. (1960), "Optimal properties of exponentially weighted forecasts," Journal of the American Statistical Association, June, 299-306.

Pearce D.K. (1984), "An empirical analysis of expected stock price movements," Journal of Money Credit and Banking, 16(3), 317-27.

Poterba J.M. and L.H. Summers (1988), "Mean reversion in stock prices: evidence and implications," Journal of Financial Economics, 22, 27-59.

Prat G. (1982), “La bourse et la conjoncture économique,” Economica, Paris.

Prat G. (1994), “La formation des anticipations boursières, Etats-Unis, 1956 à 1989," Economie et Prévision, $\mathrm{n}^{\circ} 1,101-25$.

Prat G. (2001), "Une analyse de la dynamique des primes de risque des actions suivant l'horizon de placement," Revue d'Economie Politique, 2, 291-329.

Prat G. (2007), “Les comportements boursiers sont-ils eulériens ?” Revue Economique, 58(2), 427-53.

Prat G. and R.Uctum (2008), "The dynamics of ex-ante risk premia in the foreign exchange market: evidence from the Yen/USD exchange rate using survey data," Documents de Travail EconomiX, $\mathrm{N}^{\circ} 2008-02$

Pye G. (1973), "Lifetime portfolio selection in continuous time for a multiplicative class of utility functions," American Economic Review, 63, 1013-16

Samuelson P.A. (1969), "Lifetime portfolio selection by dynamic stochastic programming," Review of Economics and Statistics, 51(3), 239-46 
Shanken J. and A. Tamyo (2011), ""Payout Yield, Risk, and Mispricing: A Bayesian Analysis," Journal of Financial Economics, forthcoming.

Shiller R. J. (2000), Irrational exuberance, Princeton University Press, Princeton New Jersey

Siegel J.J. (2005), “Perspectives on the Equity Risk Premium,” Financial Analysts Journal, 61(6), 61-71

Siegel J.J. and R.H. Thaler (1997), “Anomalies: the equity premium puzzle,” Journal of Economic Perspectives, 11 (winter), 191-200.

Shleifer, A. and L.H. Summers (1990), "The Noise Trader Approach to Finance," Journal of Economic Perspectives, 4, 19-33.

Subbotin A. (2009), Multiple Investment Horizons and Stock Prices Dynamics, PhD Thesis, University of Paris 1, December, 138 p.

Taylor M.P. (1988), "What do investment managers know? An empirical study of practitioners predictions," Economica, 55, 185-202.

Triki M.B. and N. Selmi (2009), "Long memory in stock returns: evidence of the G7 Stocks markets," Research Journal of International Studies, 9, 36-46.

Wander Weide J. and W. Carleton (1988), "Investors growth expectations: analysts versus history," Journal of portfolio Management, Spring, 78-82.

Welch I. (2000), "Views of financial Economists on the equity premium and on professional controversies," Journal of Business, 73(4), October, 501-37.

Welch I. (2001), "The equity premium consensus forecast revisited," Cowles Foundation discussion paper ${ }^{\circ} 1325$, available at http://cowles.econ.yale.edu.

Wells Fargo (2011), "Posts tagged 'equity risk premium," October

http://advisoranalyst.com/glablog/tag/equity-risk-premium/

Wilson J.W. and P.J. Jones (2002), "An analysis of the S\&P Index and Cowles's Extensions: Price Indexes and stock returns 1870-1999," Journal of Business, 75(3), 505-33. 
Table 1 - Short-term and long-term risk premia: descriptive statistics

\begin{tabular}{|c|c|c|c|c|c|}
\hline & \multicolumn{4}{|c|}{ Std deviation } & \multirow[b]{2}{*}{$\begin{array}{l}\text { Unit root } \\
\text { ADF test } \\
\text { (t-stat) }\end{array}$} \\
\hline & $\begin{array}{l}\text { Mean } \\
\text { Median }\end{array}$ & $\begin{array}{l}\text { Maximum } \\
\text { Minimum }\end{array}$ & $\begin{array}{l}\text { Skewness } \\
\text { Kurtosis }\end{array}$ & $\begin{array}{l}\text { Jarque-Bera } \\
\text { (p-value) }\end{array}$ & \\
\hline $\begin{array}{l}\text { One-year horizon } \\
\text { premium }\end{array}$ & $\begin{array}{l}5.52 \\
4.93\end{array}$ & $\begin{array}{l}14.15 \\
-8.47\end{array}$ & $\begin{array}{c}3.83 \\
-0.29 \\
3.29 \\
\end{array}$ & $\begin{array}{l}2.37 \\
0.31\end{array}$ & $\begin{array}{c}-2.91 \\
\text { (constant ; } 1 \text { lag) }\end{array}$ \\
\hline $\begin{array}{l}\text { Infinite horizon } \\
\text { premium }\end{array}$ & $\begin{array}{l}2.29 \\
2.28\end{array}$ & $\begin{array}{c}8.92 \\
-3.87\end{array}$ & $\begin{array}{l}2.17 \\
0.25 \\
3.49\end{array}$ & $\begin{array}{l}2.63 \\
0.27\end{array}$ & $\begin{array}{c}-3.06 \\
\text { (constant ; } 1 \mathrm{lag} \text { ) }\end{array}$ \\
\hline
\end{tabular}

Notes: The two risk premia are expressed in percent per month. The sample period is 1881-2008 (128 observations). The asymptotic critical values for the $\mathrm{ADF}$ test statistic is $-3.48,-2.88$ and -2.58 at the $1 \%, 5 \%$ and $10 \%$ levels, respectively.

Table 2: Estimating the one-year and infinite time horizon equity risk premia using the Kalman filter methodology

\begin{tabular}{|c|c|c|}
\hline & $\begin{array}{l}\text { one-year time horizon } \\
(\tau=1)\end{array}$ & $\begin{array}{l}\text { infinite time horizon } \\
\qquad(\tau=2)\end{array}$ \\
\hline & \multicolumn{2}{|c|}{ State equations (15) and (17) } \\
\hline$\rho_{\tau}$ & $\begin{array}{l}0.90 * * * \\
(14.4)\end{array}$ & $\begin{array}{c}0.92 * * * \\
(15.5)\end{array}$ \\
\hline$b_{\tau}$ & - & $\begin{array}{l}0.014 * * * \\
\quad(3.7)\end{array}$ \\
\hline$c_{\tau}$ & $\begin{array}{c}-10.34 * * * \\
(-41.7)\end{array}$ & $\begin{array}{c}-9.95 * * * \\
(-31.6)\end{array}$ \\
\hline
\end{tabular}

Signal equations (18) and (22)

$$
\delta_{\tau}
$$




$\begin{array}{ccc}a_{\tau, 1} & 0.151^{* * *} & 0.051 * * * \\ & (5.7) & (4.5) \\ & & \\ a_{\tau, 2} & 0.061^{* * *} & - \\ & (3.0) & \\ a_{\tau, 3} & 0.026^{* *} & - \\ & (-2.3) & \\ \alpha_{\tau, 1} & 1.39 * * * & 0.80^{* * *} \\ \alpha_{\tau, 2} & (4.4) & (2.3) \\ & 2.24 * * * & 0.46^{*} \\ \alpha_{\tau, 3} & (4.3) & (1.7) \\ & 1.85^{* * *} & 0.57 * * * \\ \alpha_{\tau, 4} & (3.8) & (2.1) \\ & 1.77 * * * & 0.85 * * * \\ \alpha_{\tau, 5} & (3.1) & (2.5) \\ \alpha_{\tau, 6} & 0.90^{* * *} & 0.93 * * * \\ \alpha_{\tau, 7} & (3.1) & (2.4) \\ c_{\tau}^{\prime} & - & 0.94 * * * \\ & & (2.9) \\ \kappa_{\tau} & - & 0.88^{* * *} \\ & 1.38^{* * *} & (3.0) \\ & (5.9) & 0.43 * * * \\ & & (2.5) \\ & 0.021^{* * *} & - \\ & (3.0) & \end{array}$

\begin{tabular}{|c|c|c|c|}
\hline \multicolumn{2}{|c|}{ covar } & \multicolumn{2}{|c|}{$\begin{array}{c}2.39 * * * \\
(5.5)\end{array}$} \\
\hline & $R^{2}$ & 0.85 & 0.77 \\
\hline & $R_{D}^{2}$ & 0.36 & 0.24 \\
\hline & $p$-value & 0.35 & 0.53 \\
\hline & $p$-value & 0.005 & 0.003 \\
\hline & AIC & & \\
\hline & $\mathrm{SC}$ & & \\
\hline & HQC & & \\
\hline
\end{tabular}

Notes Table 2 - Estimations cover the period 1881-2008 (128 years). The two signal equations (18) and (22) and the two state equations (15) and (17) are estimated as a system of four equations by using the Kalman filter methodology. covar stands for the covariance between the two signal residuals $v_{\tau t}, \tau=1,2$. The estimates are obtained by setting the covariance between the two auxiliary (state) residuals to zero. The variances of $\varepsilon_{\tau t}$ and $v_{\tau t}$ are estimated as $\exp \left(c_{\tau}\right)$ and $\exp \left(c_{\tau}^{\prime}\right)$, respectively. AIC, SC and HQC stand for Akaike, Schwarz and Hannan and Quinn information criteria for the estimated system. The initial values of $s v_{\tau t}$ have been optimized as 0.02 and 0.05 according to the minimum information criteria for $\tau=1$ and $\tau=2$, respectively. Numbers in brackets are the $t$-values. ${ }^{* *}, * *$ and $*$ indicate that estimates are significant at the $1 \%, 5 \%$ or $10 \%$ levels, respectively. $R^{2}$ and $R_{D}^{2}$ are two measures of the goodness of fit given by the signal equations (see footnote 29). $J B$ and $Q$ stand for the Jarque-Bera normality test and the Ljung-Box serial correlation test statistics, respectively. 
Figure 1 - The two components of the one year equity risk premium

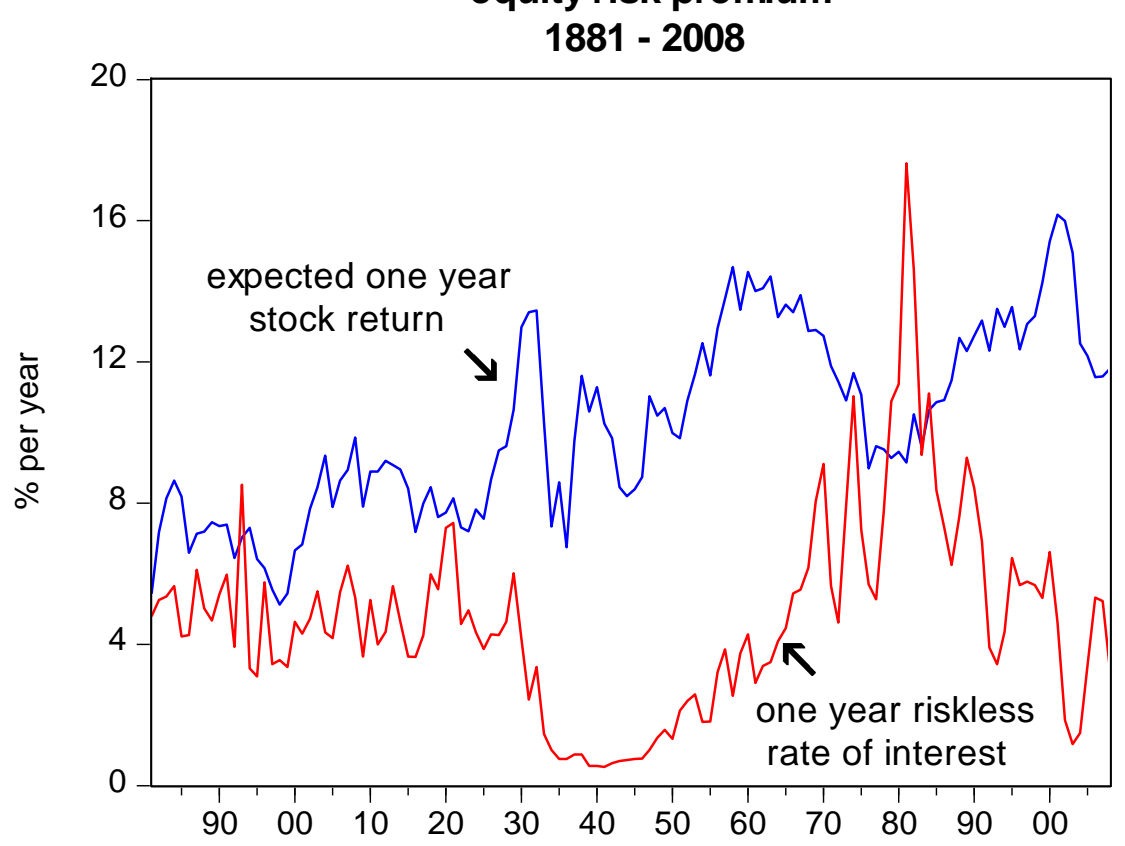

Figure 2 - The three components of the infinite horizon equity risk premium

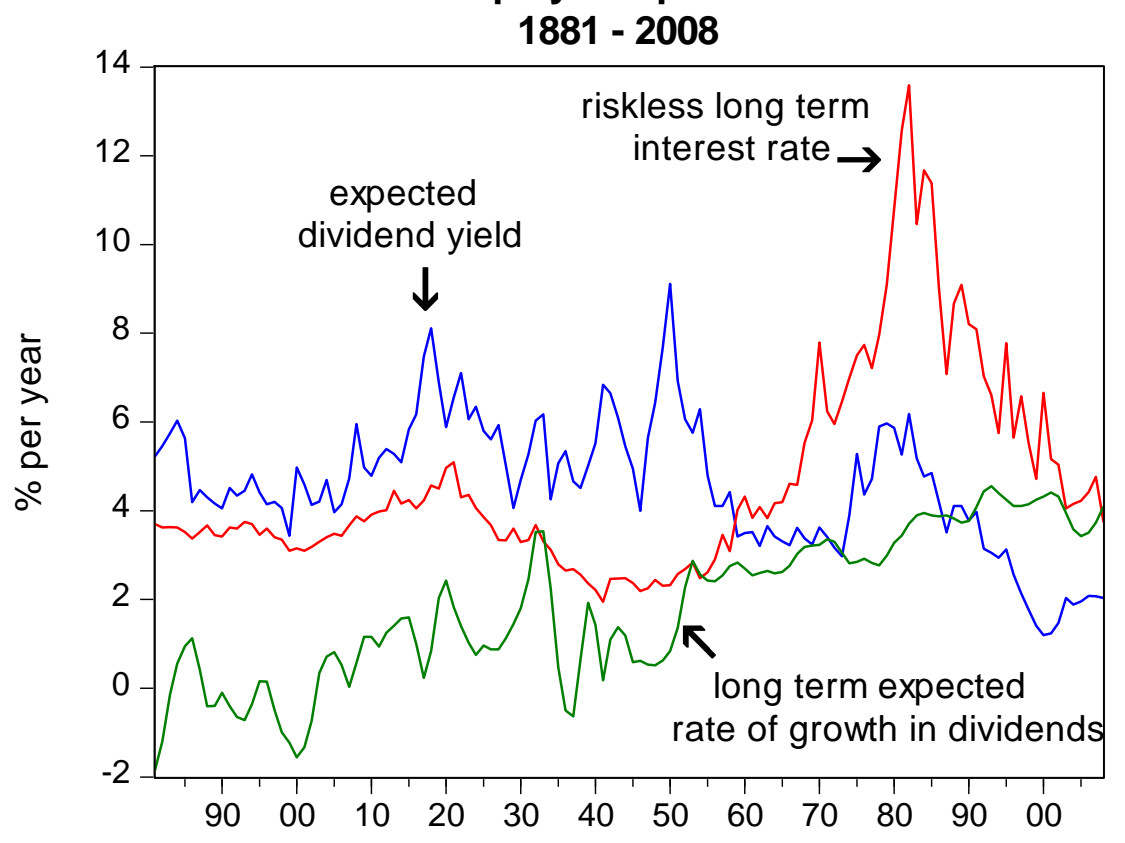


Figure 3 - The one year horizon and the infinite horizon equity risk premia

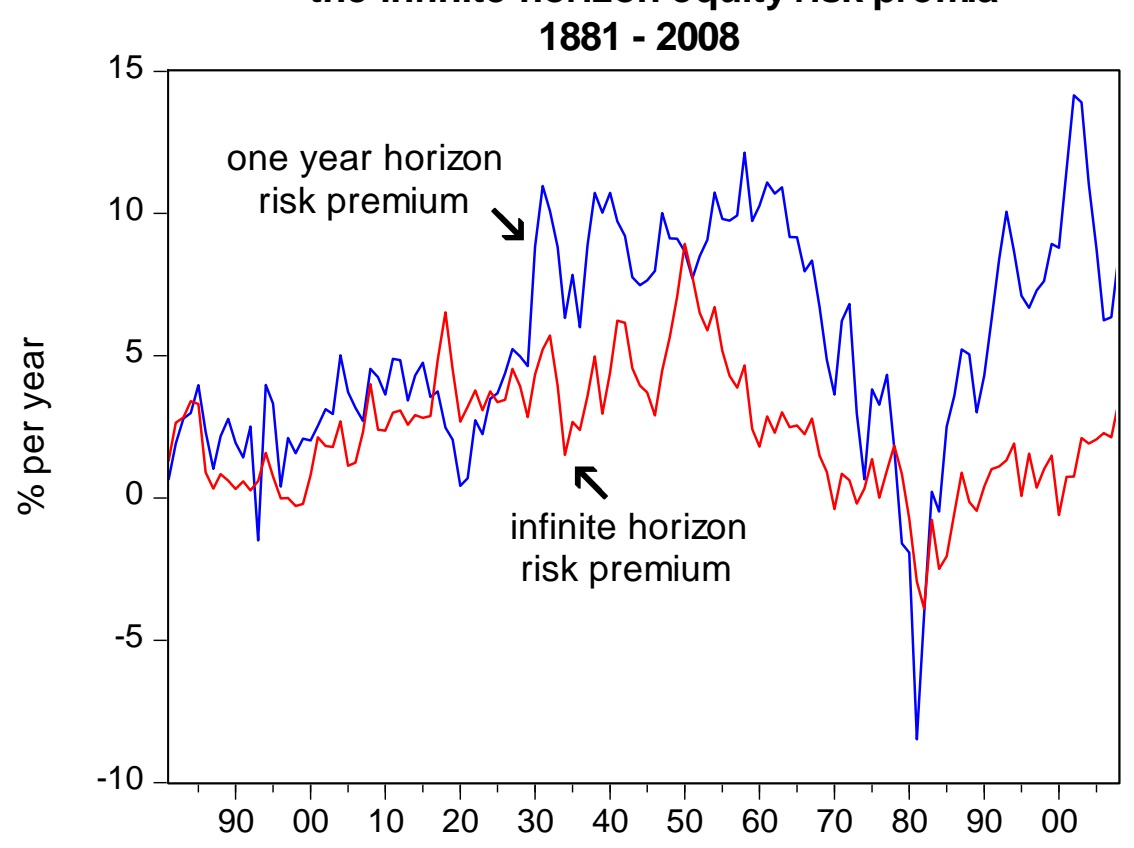

Figure 4 - Short term and long term expected variances of stock returns

1881 - 2008

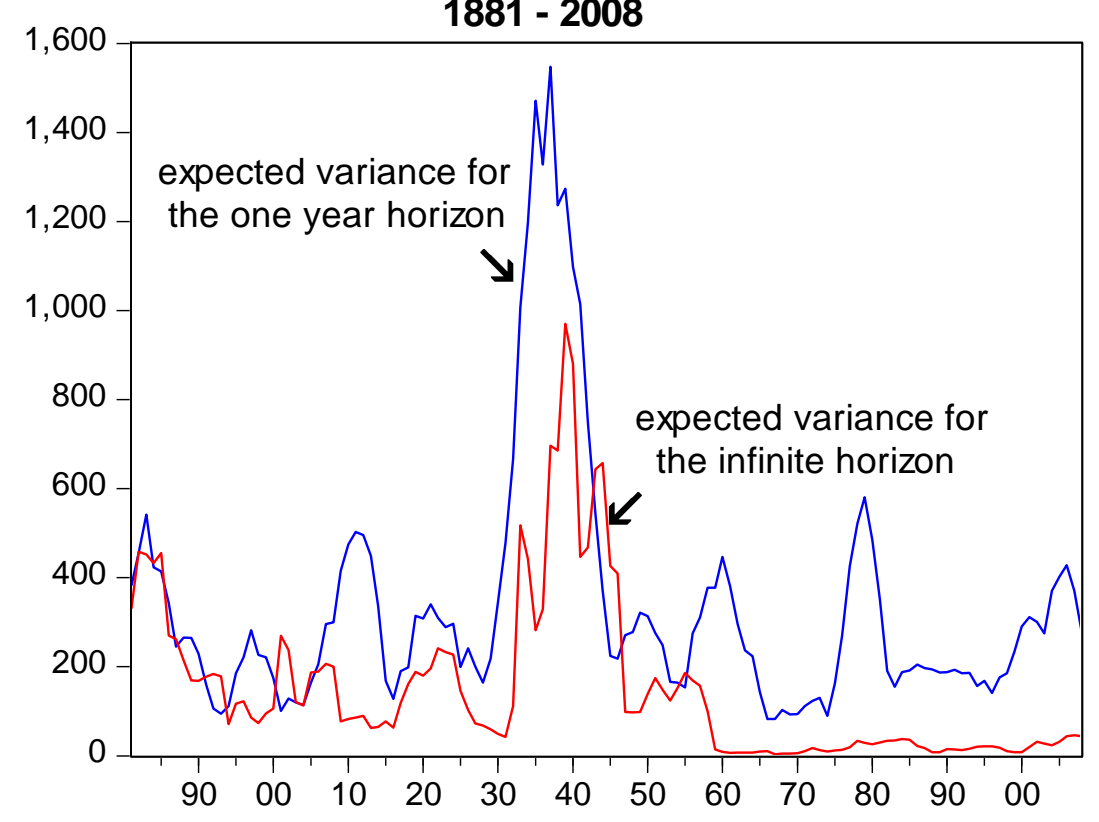


Figure 5 - Price of risk for the one year horizon 1881 - 2008

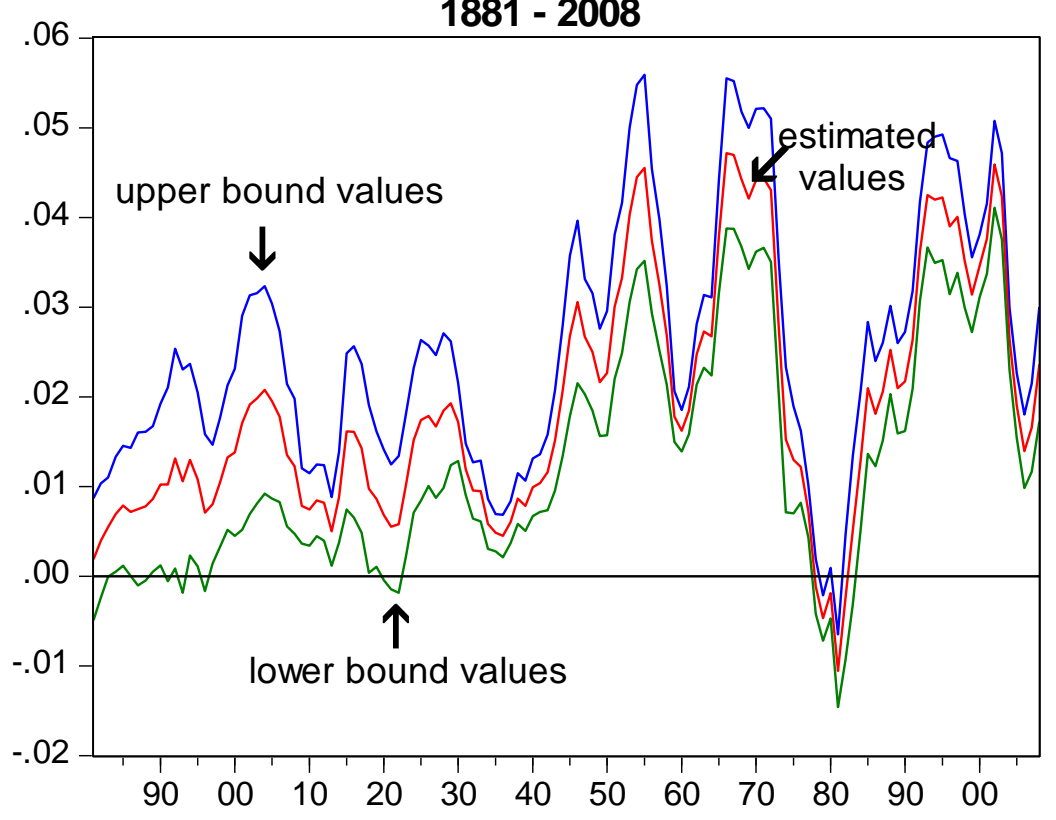

Figure 6 - Price of risk for the infinite horizon

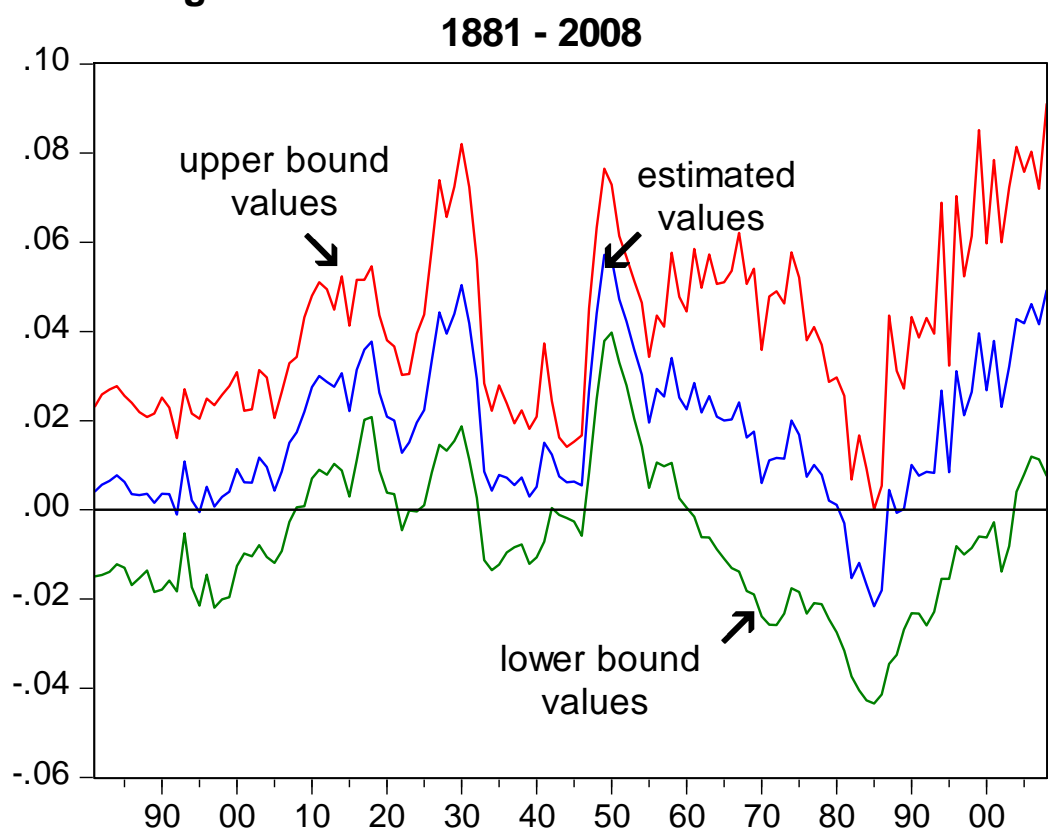


Figure 7 - The prices of risk for the one year horizon and the infinite horizon

1881 - 2008

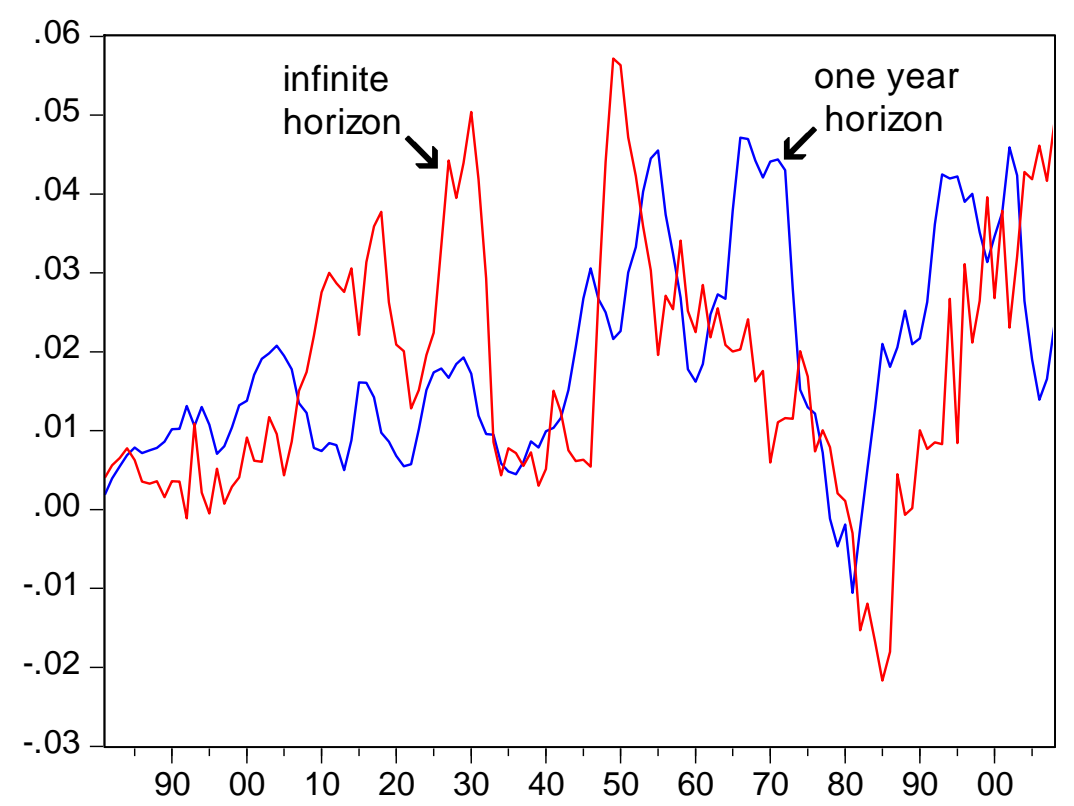

Figure 8 - Observed and fitted values of the one year equity premium

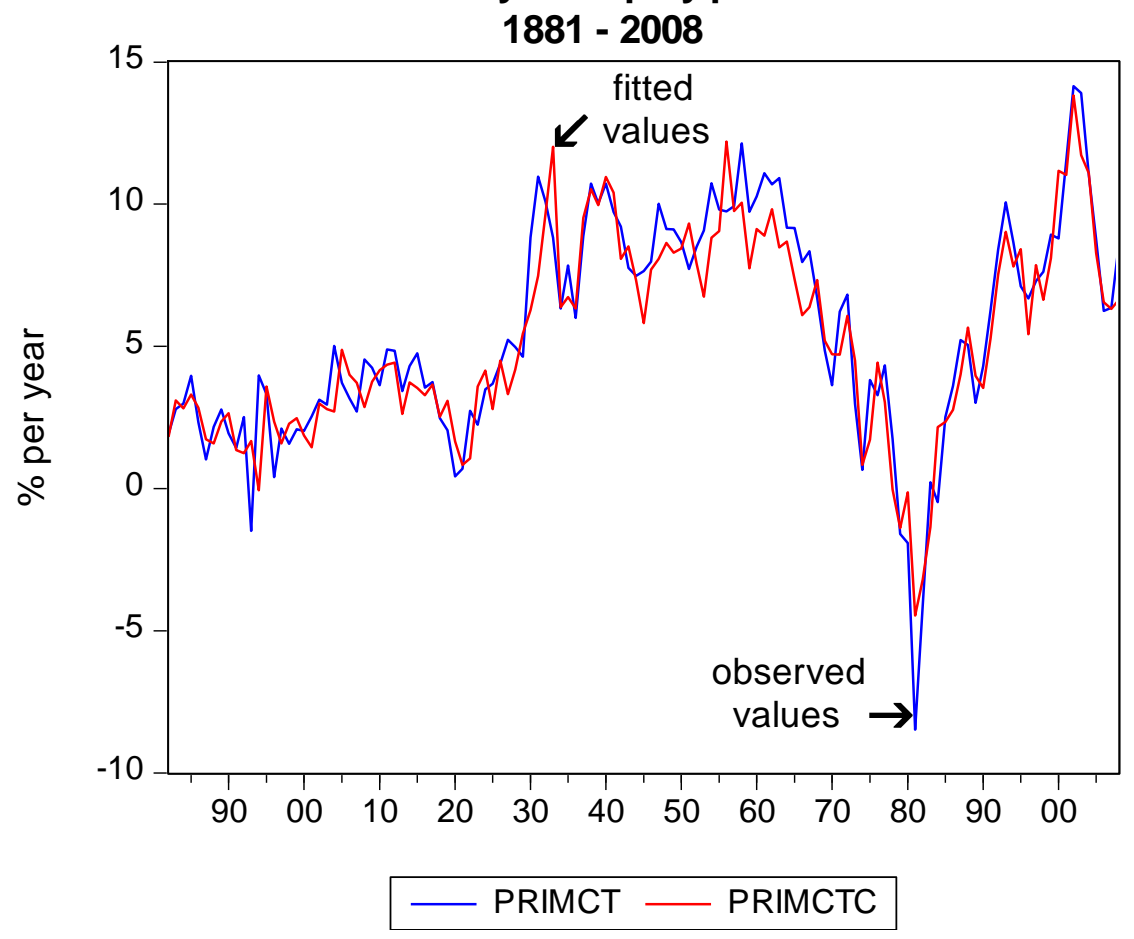


Figure 9 - Observed and fitted values of the infinite horizon equity risk premium

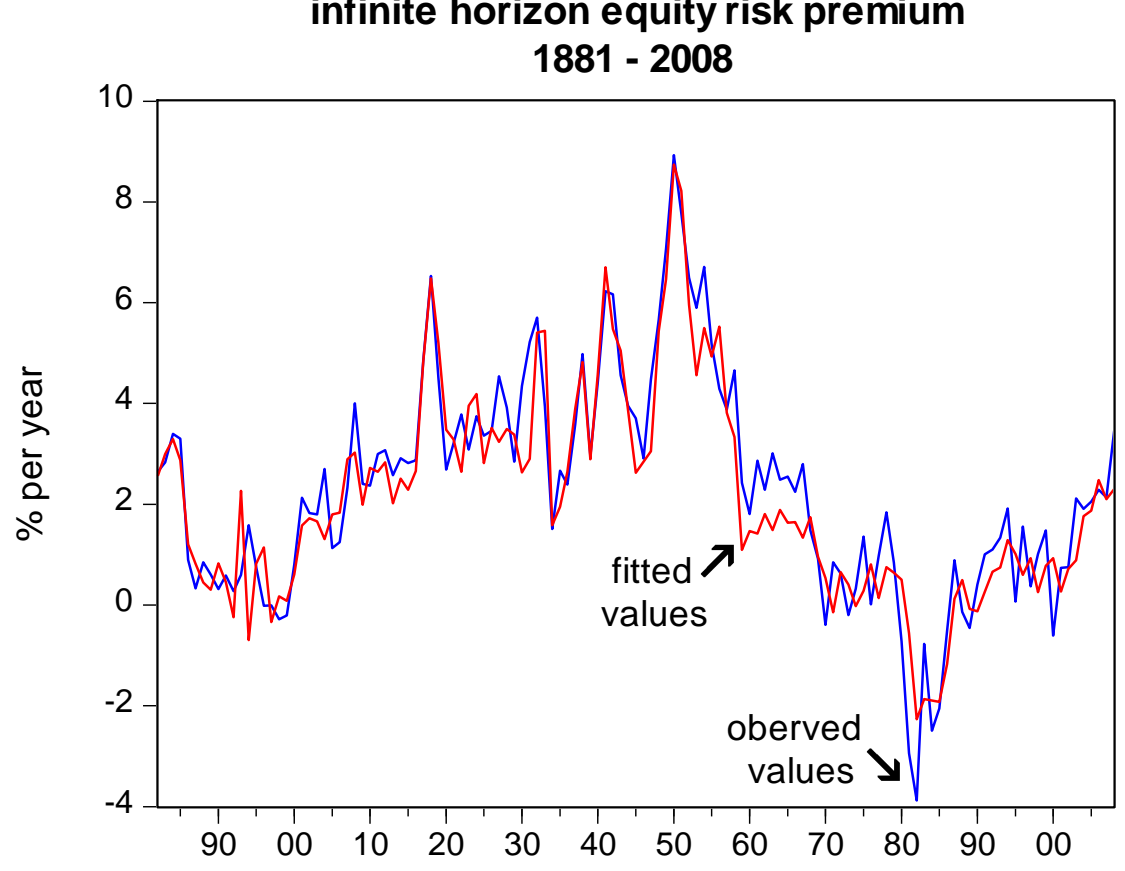




\section{WORKING PAPERS DE L'AFC}

\section{Année 2012}

WP2012-1

WP2012-2

WP2012-3

WP2012-4

WP2012-5

WP2012-6

WP2012-7

WP2012-8

WP2012-9

LuCa PENSIEROSO

"The Great Depression in Belgium: an Open-Economy Analysis"

Amélie CHARLES, Olivier DARNÉ, Claude DIEBOLT, Laurent FERRARA

"A New Monthly Chronology of the US Industrial Cycles in the Prewar Economy"

\section{Charlotte LE CHAPELAIN}

"Allocation des talents et accumulation de capital humain en France de la fin du XIXe siècle"

Claude DIEBOLT, Mamoudou TOURÉ, Jamel TRABELSI

"Monetary Credibility Effects on Inflation Dynamics:

A Macrohistorical Case Study"

\section{Thi Hong Van HOANG}

"Has Gold been a Hedge against Inflation in France from 1949 to 2011? Empirical Evidence of the French Specificity"

\section{Georges PRAT}

"Equity Risk Premium and Time Horizon: What do the U.S. Secular Data Say?"

\section{Suchit ARORA}

"Understanding Aging during the Epidemiologic Transition"

Alexandru MINEA, Antoine PARENT

"Is High Public Debt Always Harmful to Economic Growth? Reinhart and Rogoff and some Complex Nonlinearities"

\section{Claude DIEBOLT, Antoine PARENT}

"Property Rights and Early Colonization in Algeria:

The Astonishing Travel Stories of Two Precursors, Tocqueville $(1837,1841)$ and Juglar (1853)"

\section{WP2012-10 \\ Mamata PARHI, Claude DIEBOLT, Tapas MISHRA, Prashant} GUPTA

"Convergence Dynamics of Output: Do stochastic Shocks and Social Polarization Matter?"

WP2012-11 Thierry AIMAR, Francis BISMANS, Claude DIEBOLT "Economic Cycles: A Synthesis"

WP2012-12 Claude DIEBOLT

"The Cliometric Voice"
La liste complète des Working Papers est disponible sur le site www.cliometrie.org 